\title{
Apropiaciones sociales de la ciencia y la tecnología en la caficultura en la Sierra Nevada de Santa Marta (Palmor y Río Piedras, Magdalena, Colombia) $)^{1}$
}

\section{Social appropriations of science and technology in the coffee growing region of the Sierra Nevada of Santa Marta (Palmor and Rio Piedras), Magdalena, Colombia}

iD Mirleydis De La Hoz Montes²;
Astrid Lorena Perafán-Ledezma3; iD William Andrés Martínez-
Dueñas $^{4}$

Resumen

La Sierra Nevada de Santa Marta (SNSM) es un espacio de gran complejidad socio-cultural y biofísica, lo cual se ve expresado en prácticas agrícolas concretas, como la caficultura, producto de procesos sociopolíticos, economías transnacionales e intervenciones tecnocientíficas. En este artículo analizamos las relaciones sociomateriales que se dan entre los diferentes actores humanos y no humanos que participan en los procesos de transferencia de tecnología para la producción de café propiciados por la Federación Nacional de Cafeteros de Colombia y los caficultores de la SNSM (Palmor y Río Piedras, Magdalena, Colombia). De este modo se mostrará el entramado de relaciones culturales, sociales, agrícolas, políticas, tecno-científicas y económicas que reconfiguran constantemente la producción de café y la finca cafetera. El enfoque que guía este artículo se enmarca en los estudios sociales y culturales de la ciencia y la tecnología, donde la apropiación social de la ciencia y la tecnología (ASCyT) la entendemos como el proceso de encuentro, diálogo, negociación y reconfiguración de conocimientos y prácticas sobre la caficultura donde intervienen un grupo heterogéneo de actores humanos y no humanos, procesos y dispositivos sociotécnicos. El método utilizado fue el etnográfico y la revisión de archivo que permitieron explorar aspectos referentes a la historia de la conformación de estos lugares desde el siglo XIX, la producción de café y la manera como los caficultores vienen negociando y apropiando

\footnotetext{
${ }^{1}$ Este artículo es resultado de la pasantía de jóvenes investigadores Colciencias-Gobernación del Magdalena-Unimagdalena 2015, desarrollada en el marco del proyecto de investigación "Transferencia y apropiación de tecnologías en la población de caficultores campesinos de los municipios de Ciénaga y de Santa Marta en el departamento del Magdalena (Colombia)", formulado y ejecutado por el Grupo de investigación en Diversidad Humana - IDHUM y Suelo Ambiente y Sociedad - GISAS de la Universidad del Magdalena. Este proyecto cuenta con el aval del Comité de Ética en la Investigación de la Universidad del Magdalena. Los autores declaran que no tienen conflictos de interés.

2 Antropóloga, Contratista, Universidad de Magdalena, Santa Marta, Colombia. Email: mdelahozmontes@gmail.com. ORCID ID: 00000003-0283-8045

${ }^{3} \mathrm{PhD}$. en Antropología, Profesora asociada, Universidad del Magdalena, Santa Marta, Colombia. Email: aperafan@unimagdalena.edu.co. ORCID ID: 0000-0003-4377-7170

${ }_{4}^{4}$ PhD. en Antropología, Profesor Asociado, Universidad del Magdalena, Santa Marta, Colombia. Email: wmartinez@unimagdalena.edu.co. ORCID ID: 0000-0003-0921-1149
} 
conocimientos y prácticas para el cultivo del café. Como resultado se hizo visible que en los procesos de transferencia de nuevas tecnologías participan y confluyen diferentes actores humanos (caficultores, extensionistas) y no humanos (semillas, plantas, herramientas, análisis de suelos) lo cual implica diversos procesos de negociación que se expresan a través de una pluralidad de maneras en que es apropiada la tecnología por parte de los caficultores en función de aspectos políticos (conflictos internos), económicos (crisis) y ecológicos (alteraciones del ambiente). Como conclusión se propone entender la transferencia y apropiación no como la generación de productos finales que se adoptarán por públicos considerados no expertos, sino como elementos y espacios de diálogo para la negociación de la realidad en contextos social y políticamente heterogéneos; así mismo la ASCyT no sería el fin último del desarrollo científico sino una estrategia para evaluar con los diferentes actores las implicaciones de asumir tecnologías y conocimientos tecnocientíficos, evitando la homogenización epistémica y resaltando las condiciones e historias diversas que caracterizan la caficultura y sus sujetos.

Palabras clave: café; caficultores; apropiación social de la ciencia y la tecnología; ASCyT; nuevas tecnologías; Sierra Nevada de Santa Marta; Magdalena; CTS.

Tipología: Artículo de investigación

Recibido: 25/03/2019

Evaluado: $25 / 04 / 2019$

Aceptado: 29/04/2019

Disponible en línea: 02/05/2019

Como citar este artículo: De La Hoz-Montes M.; Perafán-Ledezma A.; Martínez-Dueñas, W. Apropiaciones sociales de la ciencia y la tecnología en la caficultura en la Sierra Nevada de Santa Marta (Palmor y Río Piedras, Magdalena, Colombia). Jangwa Pana, 18 (2), 182-213. Doi: http://dx.doi.org/10.21676/16574923.2925

\begin{abstract}
The Sierra Nevada of Santa Marta (SNSM) is an area of great socio-cultural and biophysical complexity, which can be seen in its concrete agricultural practices, such as coffee growing. These are a product of socio-political processes, transnational economies, and technoscientific interventions. In this article, the sociomaterial relations that are found between different human and non-human actors that participate in the processes of technological transfer for the production of coffee that was made possible by the National Federation of Colombian Coffee Growers and the coffee growers of the SNSM of the Palmor and Rio Piedras areas of Magdalena, Colombia was studied. Connections formed due to cultural, social, agricultural, political technoscientific and economic relationships that constantly reconfigure the production of coffee and the coffee farm were documented. The focus guiding this article is framed in social and cultural studies of science and technology in which the social appropriation of science and technology (SAS\&T) can be understood as a process of meeting, dialogue, negotiation and reconfiguration of knowledge and practices of coffee growing in which a heterogenous group of human and non-human actors, as well as sociotechnical processes and devices play important roles. A methodology including ethnography and document review was used that permitted the exploration of aspects of the history of the conformation of these areas since the 19th century, the production of coffee, and the ways in which coffee growers have negotiated and appropriated knowledge and practices that are important for coffee growing. As a result, it has become apparent that in the processes of transfer of new technologies, there are many human (coffee growers, extension workers) and non-human actors (seeds, plants, tools, soil analysis) that participate. This implies that there are diverse negotiation processes that are expressed in the plurality of ways that technology is appropriated on the part of the
\end{abstract}


coffee growers with respect to political (internal conflicts), economic (crisis), and ecological (environmental alteration) aspects. In conclusion, it is proposed that transfer and appropriation should not be understood in terms of the generation of final products that are adopted by non-experts users, but rather as elements and dialogue spaces for the negotiation of reality in socially and politically heterogenous contexts. Likewise, SAS\&T is not the ultimate goal of scientific development, but rather a strategy that can be used with the different actors to evaluate the implications of assuming technoscientific knowledge and technologies, as well as to avoid epistemic homogenization by highlighting the diverse conditions and histories that characterize coffee growing and its actors.

Keywords: coffee; coffee growers; social appropriation of science and technology; SAS\&T; new technologies; Sierra Nevada de Santa Marta; Magdalena; CTS; STS.

\section{Introducción}

Una de las recomendaciones que la Comisión de Ajuste de la Institucionalidad Cafetera (CAIC) realizó para superar la crisis cafetera que se dio entre 1989-2004 (CAIC, 2002) ${ }^{5}$ fue la actualización de las estrategias de transformación del cafetero campesino en empresario, como las llevadas a cabo por los programas de desarrollo rural integrado desde mediados de la década de 1970s (Escobar, 2007), por medio de la implementación de nuevas tecnologías que mejoraran la producción de café; para lo cual se debía educar al caficultor, especialmente el pequeño, en el manejo de tales tecnologías, además de brindarles el apoyo para obtenerlas y de esta manera mejorar la producción. Tras estas recomendaciones la Federación Nacional de Cafeteros (FNC) ha implementado diferentes mecanismos que le permitan al sector cafetero colombiano levantarse de la crisis, incluyendo las estrategias para agregar valor al producto de la caficultura (Muñoz, 2012: 11) a través de lo cual "el café deja de ser una materia prima corriente para convertirse en un universo de productos, servicios y experiencias que satisfacen las necesidades de los clientes y los gustos de todos los consumidores". de esta manera se fomenta la producción de una diversidad de cafés especiales que deben ser cultivados y procesados bajo estrictos estándares de calidad y procesos de certificación (Arcila, Farfán, Moreno, Salazar e Hincapié, 2007). Para que los pequeños caficultores puedan cumplir con tales estándares, la FNC ofrece a través de la extensión rural, espacios de formación o transferencia de tecnología en aspectos técnicos, ambientales y sociales, que permitan aumentar la productividad, la competitividad, la gestión empresarial y el manejo de crédito (FNC, 2011; FNC, 2014).

La zona cafetera del departamento del Magdalena (Colombia), se ubica en las estribaciones del flanco occidental de la Sierra Nevada de Santa Marta (SNSM) (Servicio Geológico Colombiano y Cenicafé, 2018), incluyendo caficultores de los municipios de Santa Marta, Ciénaga, Aracataca y Fundación, los cuales son integrados a las estrategias de optimización de la producción cafetera coordinado desde el Comité Departamental del Magdalena $^{6}$ (ver Informes de Comités Departamentales FNC,2011, FNC,2013; FNC,2014), esto incluye gestión de créditos para

\footnotetext{
${ }^{5} \mathrm{Al}$ momento de escribir este artículo las noticias nacionales e internacionales reportan una importante profundización de la crisis en la producción cafetera asociada a la desigualdad en la distribución de las ganancias que no favorecen al caficultor.

${ }^{6}$ Un comité departamental de cafeteros es una organización que agrupa productores de café con el fin de regular su producción y comercialización, esto incluye los procesos de extensión rural y transferencia de tecnología a escala departamental.
} 
que los caficultores alivien su situación financiera, capacitaciones agrícolas y empresariales; así como emisión y promoción del uso de "cédulas cafeteras inteligentes", con las que se identifica a los miembros del gremio cafetero y se regula el acceso que estos tienen a beneficios institucionales (FNC, 2013).

A través de los procesos de intervención mencionados, que incluyen un complejo conjunto de estrategias de extensión y transferencia de tecnología, se espera que los caficultores de la SNSM ajusten su articulación al mercado internacional del café, mejorando la rentabilidad del producto. No obstante, el hecho de que la tecnología sea transferida, no implica que esta sea implementada y apropiada como se lo espera, puesto que los sujetos donde se realizan los procesos de intervención tienen diferentes formas de entender y ser en el mundo. Por ello, el objetivo de este artículo es hacer visible cómo en los procesos de transferencia de nuevas tecnologías donde participan y confluyen diferentes actores ${ }^{7}$ humanos (como extensionistas, funcionarios, campesinos) y no humanos (semillas mejoradas, dispositivos de cosecha y beneficiado) y procesos (transferencia de tecnología, técnicas de recolección, beneficiado, experimentación, comercialización), se generan diversas dinámicas de negociación que se expresan a través de una pluralidad de maneras en que es apropiada la tecnología por parte de los caficultores. De este modo se evidenciará el entramado de relaciones culturales, sociales, agrícolas, políticas, tecno-científicas y económicas que configuran o reconfiguran la producción de café y cómo éste se inserta en diferentes redes socioamateriales desde la finca, hasta las acciones que se negocian en las bolsas de valores internacionales ${ }^{8}$.

\footnotetext{
7 Entendemos actor como cualquier existente (entidad, ser) vivo o no vivo que genera un efecto sobre cualquier otro existente en una red sociomaterial particular, es decir, que un actor es aquel que actúa o genera un efecto en el mundo (Latour, 2004; Martínez-Dueñas y Perafán, 2017; Perafán, 2013; Martínez-Dueñas, 2016).
}

\section{Apropiación social de la ciencia y la tecnología como espacio de diálogo y negociación}

Los estudios sobre Ciencia, Tecnología y Sociedad (CTS), entienden la ciencia y la tecnología (CyT) como un producto social e histórico que a su vez determina factores políticos y culturales, por lo tanto, los CTS no son esferas aisladas, sino co-producidas (Latour y Woolgar, 1995; García et. al., 2001, Hine, 2004; Vink 2007; Winner 1995; Pinch y Bijker, 2013); de esta manera entendemos que su desarrollo no es neutral, sino que depende de negociaciones entre grupos sociales con diferentes intereses y relaciones de poder dados en espacios y momentos específicos, que tienden a favorecer unos grupos más que a otros (Callon y Law, 1997; Escobar, 1999a; Escobar, 1999b; García et. al., 2001; Winner, 1985). En este sentido este trabajo se enmarca en la antropología de la ciencia y la tecnología (ACT), entendida como la aplicación de los métodos y teorías antropológicas para describir las redes en las que la CyT se insertan, co-producen y afectan (Latour, 2007; Latour, 2005) haciendo visible los diferentes factores socio-materiales que forman parte de dicho proceso (Haraway,2004; Escobar, 1999a, Escobar, 1999b) e involucran diferentes grupos humanos y sus formas particulares de entender y habitar el mundo (e.g. transferencia y apropiación de la CyT) (Callon y Law, 1997; Blaser, 2009).

Del lado de la transferencia y adopción de la CyT en el café, estudios recientes se han enfocado en aspectos como el impacto y monitoreo de las estrategias de programas para la capacitación agronómica de caficultores (Gathani, Gómez, Sabates y Stoelinga, 2016); adopción de prácticas para el manejo y conservación del suelo (Moreno-Seceña, Nava-Tablada y

\footnotetext{
8 Aunque el efecto de la demanda internacional de características especiales en el café afecta la forma en que se cultiva, en este trabajo solo mencionamos la relevancia de tenerlo en cuenta, puesto que nos centramos en los procesos de transferencia en la finca $y$ no en la comercialización.
} 
Hernández-Sánchez, 2015); uso y apropiación de dispositivos móviles como tabletas de información cafetera (Zapata y Marín, 2015); y establecer las característica sociales, económicas y ambientales que determinan la adopción de tecnologías para la producción orgánica (Tudela, 2015). Estos trabajos encuentran que, para garantizar procesos de adopción de tecnologías para el mejoramiento de la producción del café, son importantes factores como la "asociatividad" (asociaciones, cooperativas), fortalecer las prácticas agrícolas que se consideren las más adecuadas en el contexto concreto del agricultor y su inserción a mercados particulares, saneamiento de la tenencia de tierra y mejoramiento de las vías de transporte (Tudela, 2015). Así mismo, se evidenciaron diferentes aptitudes relativas a la conservación del suelo en función de la superficie de las fincas (Moreno-Seceña, Nava-Tablada y HernándezSánchez, 2015); finalmente Gathani, Gómez, Sabates y Stoelinga, (2016) mencionan la importancia de hacer un seguimiento intensivo al proceso de entrenamiento agronómico en la medida que esto permite tener mejores tasas de adopción. Estos trabajos se enfocan en promover o evaluar la adopción de conocimientos tecnocientíficos para el mejoramiento del cultivo del café; no obstante, nuestra atención, por el contrario, se centra en indagar cómo las personas en localidades específicas apropian o se resisten a estos procesos y en esta interacción qué nuevos conocimientos y prácticas están produciendo.

En consecuencia, nos centramos en el estudio de la Apropiación Social de la Ciencia y la Tecnología (ASCyT), donde buscamos describir las diversas maneras en que son entendidos y llevados a la práctica, conocimientos y artefactos

\footnotetext{
${ }^{9}$ La categoría no-humano hace referencia al conjunto de existentes (vivos y no-vivos; sujetos y objetos[cosas]) con los cuales los actores que se consideran humanos coexisten, intra-accionan y construyen su identidad como tales. Para una ampliación de cómo entendemos la categoría de no-humano ver Martínez-Dueñas (2012); Martínez-Dueñas (2016); Martínez-Dueñas y Perafán (2017); Martínez-Dueñas y Perafán (2018). Por su parte,
}

promovidos a través de procesos de transferencia de tecnología para la producción de café por parte de los caficultores de los municipios de Ciénaga y de Santa Marta (Magdalena, Colombia). Entendemos la tecnología como parte de un sistema sociomaterial que incluye dispositivos y organizaciones que involucran grupos heterogéneos de humanos y no-humanos ${ }^{9}$ que interactúan de formas particulares (Latour 2007; Mol, 2007; Rose, 2007; Law y Mol, 2008, Haraway, 1991). Estas articulaciones implican la negociación entre diferentes maneras de entender y habitar el mundo, dando origen a conocimientos y prácticas no[solo]modernos ${ }^{10}$ (Haraway, 1999; Blaser, 2009, Blaser, 2013; Martínez-Dueñas, 2012; Martínez-Dueñas, 2016; Martínez-Dueñas y Perafán, 2017; Martínez-Dueñas y Perafán 2018; Escobar, 2018), en esta medida nos preguntamos por los efectos en colectivos de humanos y no-humanos articulados a los procesos de transferencia de tecnologías para la caficultura sin asumirlos $a$ priori (Sting, 2015). De este modo, la tecnología a la que hacemos referencia no se limita a la "maquina", sino al conjunto de conocimientos, herramientas, técnicas, procesos organizativos y socio-culturales que producen mundos para lograr un fin esperado (Rose, 2007); en el caso del café implica desde la concepción de la finca para el caficultor, pasando por la organización de los cultivos, la maquinaria empleada, los productos que se utilizan en la producción del café, hasta los procesos de agremiación, de cooperación, de conflictos socio-ambientales y la comercialización de los productos finales.

La apropiación de las tecnologías va más allá de la comunicación de la información sobre el uso de herramientas y procedimientos

\footnotetext{
intra-acción hace énfasis en las relaciones entre diversos actores que se coproducen mutuamente (cf. Barad, 1999). 10 Entendemos no[solo]moderno cuando hacemos referencia a "mundos o naturalezas-culturas (colectividades) locales que no se adscriben, totalmente, al mundo moderno, pero tampoco pueden entenderse como intocados por éste" (Martínez-Dueñas, 2016: 35).
} 
estandarizados, que dan por sentado una incorporación lineal de los avances tecnocientíficos en las prácticas locales, dejando de lado las posibilidades de negociación entre conocimientos y mundos (Roatta, 2013; Colciencias 2010a, Colciencias 2010b, Domínguez, Echeverry y Castaño, 2013; Lozano-Borda, Pérez-Bustos y Roatta-Acevedo, 2012; Hermelin 2011; Perafán y MartínezDueñas, 2016; Martínez-Dueñas y Perafán, 2017), por tanto, la ASCyT la entendemos como el proceso de encuentro, diálogo, negociación, reconfiguración entre actores humanos y no humanos heterogéneos, procesos y dispositivos sociotécnicos y formas de conocer, de ser y de hacer (Colciencias, 2010b, Avellana y PérezBustos, 2010). Sin embargo, no se niega la importancia y pertinencia de la divulgación en el proceso de apropiación de CyT, dado que a partir de esta dinámica se propician espacios para el diálogo y negociación (Pérez-Bustos, 2014; Avellaneda y Pérez Bustos, 2010).

De esta manera se propone un modelo de ASCyT en el que los conocimientos otros, al igual que los conocimientos tecnocientíficos sean tomados en cuenta del mismo modo, generando diálogos, que no necesariamente tengan un objetivo predefinido desde la tecnociencia, sino que se constituyan en espacios de encuentro (Colciencias, 2010b; Martínez-Dueñas y Perafán, 2017; Martínez-Dueñas, 2016; Haraway, 1999) y en los que se tenga en cuenta que la relación de diferentes realidades sociales con los diversos sistemas tecnológicos generan "pluralidad de apropiaciones" (Colciencias, 2010b), así como de malentendidos (Blaser, 2009), de la misma manera que cualquier objeto se integra de maneras inesperadas a dinámicas sociomateriales particulares (Mol, 2007; Callon, 1999; Castells, 2001). Así, en este artículo abordamos el proceso de ASCyT, en el que se evidencian multiplicidad de relaciones entre la FNC, los expertos, los campesinos, los sistemas tecnológicos y demás actores que hacen parte de los entramados socio-materiales en la producción cafetera.

\section{Metodología}

Actualmente el café se constituye en el principal cultivo que se produce en las estribaciones de la SNSM, donde el departamento del Magdalena cuenta con un total de 19.400 ha de café (FNC, 2018), con un promedio de 6,6 ha por finca (la más alta del país) (FNA, 2008) y es la actividad a la cual se dedica la mayor parte de la población (Viloria, 2005). La FNC organiza el territorio cafetero en unidades espaciales administrativas denominadas distritos, los cuales se encuentran conformados por fincas contiguas de un mismo municipio. En el departamento del Magdalena existen once (11) distritos cafeteros, a los que se les asignan extensionistas (profesional agropecuario), encargados de actualizar la información cafetera, la realización de visitas técnicas y de transferir los conocimientos y tecnologías desarrollados por el Centro Nacional de Investigaciones del Café (Cenicafé ${ }^{11}$ ) y promovidas por FNC.

Esta investigación se centró en el distrito Palmor del municipio de Ciénaga, conformado para el año 2016 por 514 fincas y 1.924 ha sembradas de café y el distrito Río Piedras del municipio de Santa Marta, conformado por 501 fincas y 1.949 ha sembradas de café (Sica, 2016). Estos dos distritos se encuentran ubicados entre los $800 \mathrm{y}$ los 2.000 msnm (Fig. 1).
${ }^{11}$ Cenicafé fue creado en 1938 por la FNC para "estudiar los aspectos relacionados con la producción en las fincas, la cosecha, el beneficio, la calidad del grano, el manejo y la utilización de los subproductos de la explotación cafetera, y la conservación de los recursos naturales de la zona cafetera colombiana" (https://www.cenicafe.org). 
Figura. 1 zona Cafetera del Departamento del Magdalena.

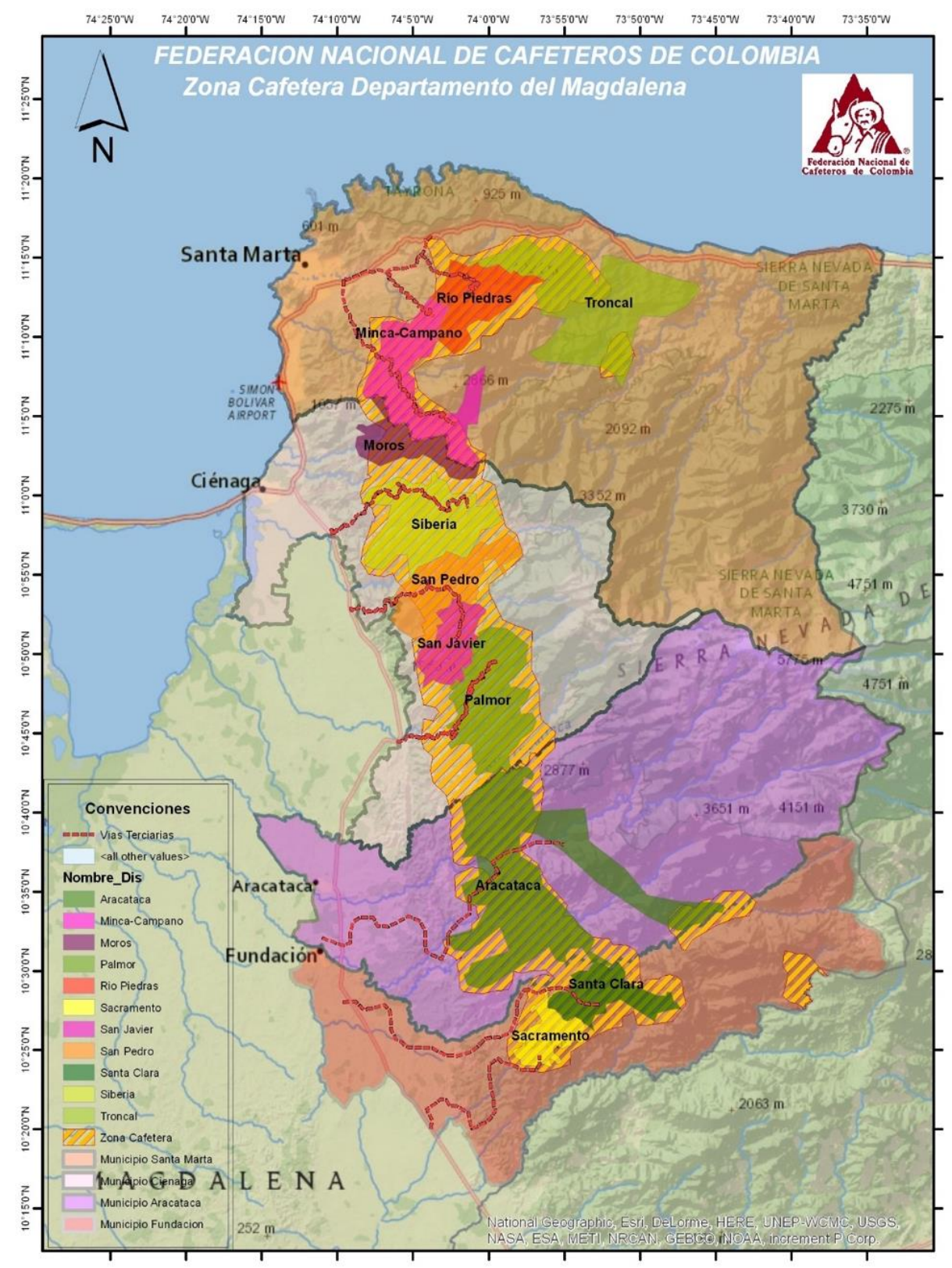

Fuente: Sistema de Información Cafetera (Sica) de la FNA (Sica, 2017).

El trabajo de campo en estos dos distritos se realizó en el año 2017. Se levantó información referente a: la conformación social de estos lugares, el proceso de transferencia de tecnología, las prácticas agrícolas en torno al cultivo del café y el modo de vida de los caficultores, con el fin de evidenciar las maneras en que los caficultores de los municipios de
Ciénaga y Santa Marta están apropiado las nuevas tecnologías transferidas por la FNC; para ello se realizaron varias visitas a estos lugares en algunos acompañados por el extensionista encargado de la zona. Esto permitió reunirse con diferentes familias caficultoras, conocer el proceso de transferencia de tecnología a través de prácticas concretas en las fincas y en espacios 
de capacitación organizados por la FNC. Durante estas visitas también se pudo observar y vivenciar los procesos y prácticas asociados al ciclo de producción del café, lo cual fue posible a través de recorridos, conversaciones informales, 22 entrevistas (de las cuales 10 fueron realizadas durante visitas a fincas en Rio Piedras y 12 en Palmor), se participó en cinco talleres de capacitación (dos en Palmor y tres en Río Piedras) y 8 demostraciones de métodos (tres en Río Piedras y cinco el Palmor) (PerafánLedezma y Martínez-Dueñas, 2019; MartínezDueñas, 2016; Guber, 2005; Russi, 1998; Gómez, Rodríguez y Alarcón, 2015, Marcus, 2001), evidenciando las diferentes relaciones que se establecen entre distintos actores humanos y no humanos como los extensionistas y funcionarios de la FNC, caficultores, semillas, plantas, análisis de suelo, cultivos asociados, el clima, arvenses, patógenos y el manual cafetero, por mencionar algunos (Latour, 2005). Lo anterior se complementó con cinco entrevistas semiestructuradas realizadas a funcionarios de la FNC (Magdalena). (Perafán-Ledezma y Martínez-Dueñas, 2019; Galindo, 1998), que nos permitieron conocer algunos de los lineamientos y políticas específicas sobre transferencia de nuevas tecnologías en el sector cafetero y evidenciar cambios vividos en la caficultura de estos lugares. También se implementó la historia de vida (Aceves, 1998), para hacer visible, desde las experiencias de los sujetos, las formas de transferencia y de adopción de nuevas tecnologías para la producción del café. En todos los casos de informó a los interlocutores sobre el proyecto y sus propósitos y se solicitó consentimiento informado para registrar la información. Cómo parte de este trabajo se desarrolló el "Primer Encuentro Construyendo Conocimientos Regionales en Torno al Café: Experiencias en la Sierra Nevada de Santa Marta $^{12 "}$ (Universidad del Magdalena, Santa

12 Conversatorio que contó con el apoyo de la Dirección de Transferencia, Apropiación y Propiedad intelectual de la Universidad del Magdalena, la Federación Nacional de Cafeteros de Colombia, la Cooperativa de Cafeteros de la Costa Caficosta, CooagroNevada, la Red de Productores Ecológicos de la Sierra Nevada de Santa Marta Red
Marta, 2017) que contó con la participación de caficultores y extensionistas de la SNSM, así como de directivos de la FNA y actores académicos. Este evento se realizó con el objetivo de visibilizar las diferentes dinámicas que se generan a partir de la transferencia y apropiación de tecnologías que son aplicadas a la producción de café en la SNSM, así como conocer los diferentes significados que puede llegar a tener el café para los diferentes actores que intervienen en el proceso la producción del grano.

\section{Resultados}

\section{Elementos históricos y sociales sobre los distritos Palmor y Río Piedras}

"Sembrar café en la Sierra Nevada de Santa Marta no es lo mismo que sembrarlo en el Eje Cafetero Colombiano", fue una frase recurrente durante los recorridos por Río Piedras y Palmor, haciendo referencia a las particulares condiciones geográficas, climáticas y culturales de este macizo montañoso. A diferencia de otras zonas cafeteras de Colombia, en la SNSM el cultivo del café tiene sólo una cosecha en el año (monomodal) que tiene lugar entre los meses de octubre y marzo, con un rango de variaciones según la altura a nivel del mar, el flanco del macizo y la pluviosidad (FNC, 2009). A esto se suma que los productores de café de estas zonas de la SNSM proceden de diferentes departamentos de la región andina del país como Tolima, Antioquia, Huila, Santander y Caldas, quienes conservan costumbres de sus lugares de origen, por lo que las prácticas para sembrar café y la relación con este cultivo pueden variar de finca en finca. En esta medida es importante hacer una breve contextualización de la conformación de estos dos lugares en la SNSM,

EcolSierra, la Asociación de Productores Orgánicos de la Sierra AsoproSierra, la Cooperativa Cafetera de la Costa y la Cooperativa de Cafés Especiales Sierra Nevada Coocafé. 
que permita entender, cómo se han configurado las prácticas asociadas al café, los diferentes actores implicados y las dinámicas de apropiación y reconfiguración de las nuevas tecnologías para la producción del café.

\section{La llegada del café a Río Piedras y Palmor}

Se estima que el café se siembra en la SNSM desde el siglo XVIII (FNC, 1958), pero su explotación comercial iniciaría en el siglo XIX por medio de un proceso colonizador planificado, mediante la creación de haciendas cafeteras en los departamentos del Magdalena y el Cesar, liderado principalmente por migrantes provenientes de Alemania, Rusia y Norte América, lo que permitió que para principios del siglo XX el café se tornara en un sector productivo importante en este territorio (FNC, 2016a; Viloria, 2005, 1998, 1997, PosadaCarbó, 1993; Monsalve, 1927; Friede, 1963). En lugares como Palmor y Río Piedras la llegada del café fue más tardía y está relacionada con dinámicas sociales particulares como las guerras bipartidistas de la primera mitad del siglo XX, la demanda de mano de obra para trabajar en las haciendas cafeteras, la migración espontánea de población en busca de nuevas oportunidades económicas y la ocupación de terrenos baldíos. Tanto Palmor, como Río Piedras son zonas conformadas por personas que, en un gran porcentaje, llegaron desplazadas por procesos violentos del interior del país, de regiones como Antioquia, Caldas, Huila, Santander y Tolima, quienes a su llegada se vincularon como trabajadores en las grandes haciendas de café; posteriormente lograron adquirir o arrendar tierras para sembrar sus propios cultivos de café, como fue el caso señor Bernardo Orjuela, uno de los primeros habitantes de Palmor, quien en la década de 1960 migró hacia la SNSM, llegando primero a San Pedro de la Sierra, donde fue contratado en una finca cafetera, lugar donde realizaba diferentes labores. Después de unos años reunió el capital suficiente para comprar un lote de dos hectáreas en el Palmor, lo que le posibilitó iniciar su propio cultivo de café. Esta historia se repite en muchos relatos de habitantes de estos lugares de la SNSM. Sin embargo para otros caficultores de Palmor y Río Piedras, fueron otras razones las que los motivaron a migrar al macizo, como el ser invitados por familiares y/o amigos, ya que vieron en estos lugares oportunidades de progreso, debido a la presencia de terrenos "vírgenes" y fértiles con características excepcionales para sembrar café, incluyendo el poco trabajo que este demandaba; así este territorio les dio la posibilidad de comenzar una vida nueva, de "hacer finca" y "tener rancho[lugar de habitación propio]". Comienza por tanto la conformación de los centros poblados, entre ellos el Palmor, la apertura de carreteras y mantenimiento de las mismas, construcción de escuelas, negocios para la compra de café, tiendas de comestibles y productos de uso doméstico, construcción de abastecimientos de agua y de una hidroeléctrica en el Palmor; todo esto atravesado por procesos organizativos como las juntas de acción comunal, cooperativas y asociaciones, correlacionadas con lazos de parentesco. En la actualidad el municipio de Palmor es conocido como la Capital Cafetera de la SNSM ya que ahí se concentra un alto porcentaje de las transacciones comerciales en torno al café en el Magdalena.

Al igual que el señor Bernardo, diferentes habitantes tanto del Palmor, como de Río Piedras, mencionan que el café llegó a estas zonas a mediados del siglo XX, traído por los colonos que trabajaban en haciendas como la Victoria, Cincinnati, Vista Nieve, El Recuerdo, Minca, María Teresa, Jirocasaca, Onaca, las Nubes y Manzanares.

Para entonces el cultivo del café, se daba de acuerdo con sus habitantes de forma muy sencilla y tradicional, la cual consistía en esparcir las semillas sobre el terreno o sembrar a partir de estacas, procesos que no requerían de semillero, germinador y abono. Los caficultores mencionan, además, que no era necesario la 
aplicación de abonos, las enfermedades del café no estaban presentes, la producción de las plantas era superior a la actual, la variedad vegetal que se sembraba era la arábiga tradicional o típica, las labores de mantenimiento que se hacían al cafetal no superaban las limpias, es decir el corte de la maleza. La siembra de café se hacía a partir de los conocimientos que los colonos que se asentaron en estos dos territorios cafeteros habían heredado de sus padres caficultores y que habían traído consigo de sus lugares de origen o que aprendieron trabajando en las grandes fincas cafeteras en la SNSM, así como de los adquiridos con la experiencia.

Sin embargo, la forma como se produce el café en la SNSM ha venido cambiando a partir del momento en que la FNC hace presencia en la zona a través de sus programas de extensión agrícola para mejorar la productividad de las fincas cafeteras. Muchos de los productores jóvenes de Palmor y Río Piedras recuerdan en su niñez ver a sus padres asistir a reuniones y actividades de formación lideradas por el Comité Departamental de Cafeteros del Magdalena; por su parte, los productores y extensionistas mayores mencionaron que la FNC ha hecho presencia en las zonas estudiadas desde que inicia la producción de café y resaltan el papel de dicha institución en la construcción de vías de acceso y de escuelas, que hasta el momento siguen funcionado. Estos procesos de extensión se han mantenido en el tiempo a pesar de que en la década de 1970 se dio un proceso de reconfiguración socio-político y económico de la zona debido a cultivos uso ilícito, lo cual se articuló al conflicto armado que tuvo su periodo más fuerte entre los años 1980 y el 2002 (Villarraga, 2014).

En las conversaciones con los productores mayores se tiende a recordar la figura de los prácticos, quienes eran productores que habían sido formados por la FNC, a través de la Fundación Manuel Mejía ${ }^{13}$, en prácticas de cultivo certificadas por Cenicafé y se constituían de esta manera en extensionistas de la zona donde habitaban; para su formación el Comité Departamental de Cafeteros los transportaba a la sede principal de Cenicafé en Chinchiná (Caldas) (centro del país) con el fin de impartirles conocimientos tecnocientíficos mediante cursos prácticos, dado que la gran mayoría de los productores no sabían leer ni escribir. Sin embargo, la presencia de los prácticos desaparece, pues se regula el trabajo del servicio de extensión a través de profesionales de las ciencias agrarias quienes comienzan a acompañar y direccionar todo lo referente al cultivo del café. De este modo, se generan importantes transformaciones en los procesos de producción del café, la articulación con los productores y nuevas prácticas e interacciones sociotécnicas en la SNSM.

\section{Transfiriendo y apropiando}

Para el cultivo del café en Colombia, la FNC ha establecido parámetros a partir de los cuales se controla cada etapa de producción, definiendo de esta manera unos procesos que permiten tecnificar y potenciar el proceso, desde la escogencia de la semilla hasta la comercialización del producto; esto se hace a través de la extensión rural la cual busca la transferencia y adopción de nuevas tecnologías para la producción de café:

La extensión rural se constituye en un sistema o servicio que, mediante procesos educativos, ayuda a la población rural a mejorar los métodos y técnicas agrícolas, aumentar la productividad y los ingresos, mejorar su nivel de vida y elevar las normas educativas y sociales de la vida rural (FNC, 2015:1).

\footnotetext{
${ }^{13}$ Fundación creada en la década de 1960 cuyo objetivo es generar procesos de formación y capacitación agropecuario con énfasis en la caficultura.
} 
A través del servicio de extensión se llevan a cabo el programa de transferencia de conocimientos y tecnologías para mejorar la producción del café, haciendo uso de recursos educativos no-formales (métodos en campo como talleres y demostraciones), mediante métodos individuales y grupales, que permitan llegar al mayor número posible de productores. Según el actual Plan Operativo de Desarrollo Rural (FNC, 2016b), la transferencia de tecnología es el programa al que más tiempo se le dedica por parte del servicio de extensión de la FNC, pues lo que se pretende es brindar un asesoramiento integral en términos técnicos, económicos, sociales y ambientales, realizando un acompañamiento al caficultor, con el fin de generar cambio técnico en la producción del café. La tecnología que se trasfiere incluye el uso de artefactos (herramientas, maquinas, semillas, arreglos agrícolas, finca ${ }^{14}$ ) y todo un conjunto de conocimientos técnicos y científicos que son aplicables al establecimiento, manejo y mantenimiento de cultivos. Por ejemplo, la FNC transfiere el diseño para la construcción de los semilleros incluyendo algunos materiales y las semillas modificadas ${ }^{15}$ de café, que transforman las dinámicas del cultivo, incluyendo el intercambio de semillas, su cuidado y el uso de la finca. Hasta el momento, como menciona el señor Edgar Ramírez ${ }^{16}$, director del Comité de cafeteros del Magdalena, la FNC no cuenta con un método para medir la implementación de los conocimientos transferidos, por lo que menciona que la forma de evaluar el programa es por medio de la prueba de taza ${ }^{17}$ que se realiza al café para ser vendido, en la cual se analiza la

\footnotetext{
${ }^{14}$ Entendemos la finca como una entidad socio-material producto de las intra-acciones entre humanos y no humanos en un espacio específico, en esa medida, es hecho, poder y discurso, un factiche, por lo tanto, un artefacto (cf. Latour, 2007; Blaser, 2009; Barad, 1999).

${ }^{15}$ Semillas producidas a través de polinización y selección artificial de las plantas, para obtener una nueva variedad de café Ver: Cenicafé (2012). Variedad Castillo: preguntas frecuentes. Boletín técnico 426. Manizales-Caldas. 2012. ${ }^{16}$ En comunicación personal con Edgar Ramírez (Director Ejecutivo del Comité de Cafeteros del Magdalena) el 13 de diciembre de 2016, Santa Marta, Magdalena.
}

calidad del mismo y los atributos organolépticos que determinaran el valor agregado del producto (Alvarado-Alvarado, Moreno-González, Montoya-Restrepo y Alarcón-Suárez, 2009), considerando que a mayor calidad, mayor es la implementación de los conocimientos y herramientas técnicas transferidas; en este sentido el esfuerzo de regular tecnocientíficamente la producción se valida a través del subjetivo proceso de catación.

El servicio de extensión de la FNC ha sido estructurado teniendo en cuenta, por un lado, un plan operativo (programa de actualización de la base de datos SICA, gestión empresarial, transferencia y cafés especiales) en el que se definen unos programas para conocer e intervenir los modos de vida de los caficultores y sus prácticas de cultivo; y por otro lado, una planeación precisa del proceso educativo, cuyo fin último es lograr que el caficultor adopte las nuevas tecnologías. Dentro de esta planeación se define una línea de acción para la adopción de la tecnología, pues se parte de la idea que "el proceso de adopción se da paso por paso" (FNC, 2015:3). En dicha línea de acción se tiene en cuenta el conocimiento del caficultor y su posición frente a los conocimientos "teóricoscientíficos"; este último es impartido en etapas de acuerdo con el cambio de actitud y el interés que se observe en el caficultor respecto al conocimiento científico; de este modo la adopción de los sistemas tecnológicos transferidos se da a través de la experimentación (enseñanza no formal ${ }^{18}$ ). La FNC lo expresa de la siguiente forma (Fig. 2):

\footnotetext{
${ }^{17}$ La prueba de taza es la evaluación que un catador realiza al café, a través de la vista, tacto, olfato y gusto, que permite identificar las características propias de éste, las cuales están determinadas por la variedad botánica, el clima y suelo. Con esta prueba se identifica otras cualidades o defectos del producto como manejo del cultivo, modos de recolección y procesamiento del café. El resultado de esta prueba se presenta en lo que denominan perfil de taza.

${ }^{18}$ En la extensión rural se han planteado diferentes métodos para que el caficultor adopte los conocimientos y tecnologías en cada una de las etapas del proceso de
} 
Figura. 2. Proceso de adopción de tecnologías de acuerdo con la Federación Nacional de Cafeteros.

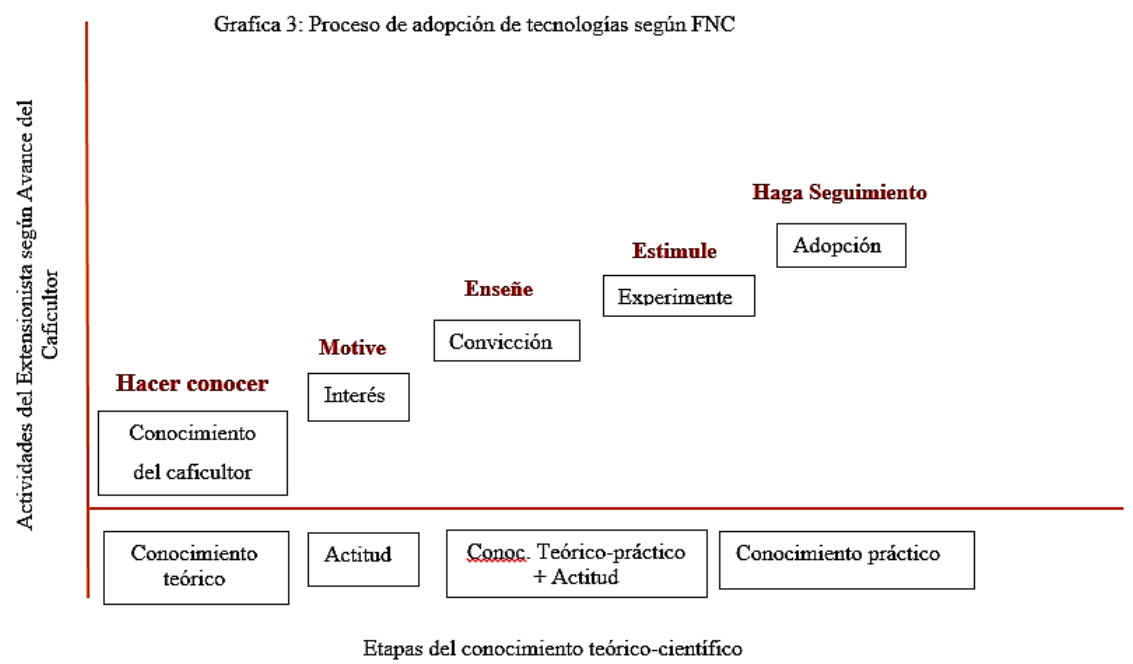

Fuente: FNC, 2015:4

Con este proceso lo que se busca es que el caficultor conozca e incorpore conocimientos tecnocientíficos agrícolas para que pueda remplazar o mejorar los conocimientos llamados "tradicionales" y así aumentar la eficiencia y rentabilidad del cultivo; como lo plantea el extensionista Alex Saurith

[...] la extensión rural lo que hace es transferir conocimientos a los agricultores, llevar toda la tecnología, toda la información que, en nuestro caso de Federación, genera CENICAFÉ. Todo lo que nosotros hablamos tiene que ser con bases científicas e investigativas, aquí no podemos venir nosotros a improvisar, ni venir Lucho ni James ${ }^{19}$ a decir que esta práctica se hace bajo un criterio que él cree. Y si no está dentro de los criterios de CENICAFÉ, está mal, está muy mal (en comunicación personal el 17 de marzo de 2017).

producción. Tales métodos son: 1) individuales (visitas a finca, visitas a oficina); 2) grupales (grupos de demostración de métodos o resultados, reuniones, giras, días de campo, cursos cortos); y 3) masivos (folletos,
Sin embargo, dentro de este proceso no se descartan todos los conocimientos llamados tradicionales, pues algunos pueden ser validados e implementados, este mismo extensionista comenta:

[...] Muchas de esas prácticas [tradicionales] hay que seguirlas implementando. Mira, el manejo del sombrío. (en comunicación personal el 17 de marzo de 2017).

De esto modo la FNC, no sólo se encarga de transferir nuevos sistemas tecnológicos, sino también de regular y optimizar prácticas tradicionales que pueden ser ventajosas para el cultivo de café; lo que Rabinow (1996) llama actualización y que se identificó para el caso de semillas andinas en el Macizo Colombiano (Perefán, 2013; Perafán y Martínez-Dueñas, 2016).

De este modo, cada uno de estos procesos ha sido planeado y estructurado a través del

plegables, periódicos, cartillas, videos, programas de radio y televisión).

${ }^{19}$ Extensionistas a cargo del Corregimiento de Palmor. 
conocimiento técno-científico, no obstante, la manera en que estos se implementan en la práctica puede variar de acuerdo con la relación que los productores establezcan con la transferencia (cf. de Certeau, 2000). En este respecto, a continuación, se presentan algunos de dichos procesos, discursos y dispositivos que conectan las directrices establecidas por la FNC, y que se expresan a través, por ejemplo, del Manual del Cafetero ${ }^{20}$ (FNC-Cenicafé, 2013a, $2013 b, 2013 c)$ y los modos en que son acogidos por los caficultores de Río Piedras y de Palmor, evidenciando a su vez, muchas de las dinámicas de apropiación de la CyT en la producción del café, producto del encuentro entre los conocimientos y prácticas tecnocientíficos promovidas por los extensionistas y los de los productores.

\section{Germinador o Semillero}

En esta primera etapa del proceso de producción de café, los caficultores deben preparar el terreno y escoger la semilla a sembrar y garantizar las condiciones para que germine adecuadamente. La FNC recomienda a través de los extensionistas, el Manual del Cafetero (FNCCenicafé, 2013b), los boletines técnicos ${ }^{21}$, programas de televisión (El Profesor Yarumo), entre otros, que se usen solamente las semillas producidas y certificadas por Cenicafé, como las variedades Tabi, Colombia, Castillo y Cenicafé1, por ser resistentes a enfermedades como la roya, garantizar una mayor producción y una mejor calidad de la taza. Actualmente la FNC recomienda en la SNSM la siembra de las variedades Castillo y Cenicafé1, ya que son

${ }^{20}$ El manual del cafetero colombiano es un conjunto de tres tomos sobre la caficultura incluye recomendaciones prácticas, manejo sostenible y los procesos involucrados en la producción del café. Recopila investigaciones desarrollas por Cenicafé y se plantea como una fuente de consulta permanente tanto para los extensionistas, como para los caficultores para la toma correcta de decisiones (FNC-Cenicafé (2013a).

${ }^{21}$ Los boletines técnicos o avances técnicos son publicaciones realizadas por Cenicafé referente a temas agrícolas asociados al café que están dirigidos a personas resistentes a la enfermedad de la cereza del café $(\mathrm{CBD})^{22}$. Además, se recomienda a los caficultores seguir el Manual Cafetero para la construcción de los semilleros, los cuales deben ser ubicados a $40 \mathrm{~cm}$ del suelo, con $30 \mathrm{~cm}$ de profundidad, contar con una capa de gravilla de $1 \mathrm{~cm}$ de grosor y un sustrato de $20 \mathrm{~cm}$ de arena fina de río (FNC-Cenicafé, 2013b). De igual forma se deben seleccionar semillas adecuadas para garantizar plántulas en óptimas condiciones y un desarrollo radicular apropiado para no afectar la edad productiva o la capacidad de producción de la planta (Gaitán, Villegas, Rivillas, Hincapié y Arcila, 2011). Con base en esto los extensionistas recomiendan a los caficultores no obtener semillas de sus propios cafetales, ya que no siempre las podrán procesar de forma correcta. El extensionista persuade a los caficultores a sembrar las semillas producidas por Cenicafé, ya que son confiables para garantizar una producción sin mayores contratiempos.

Si bien los caficultores de manera constante están en contacto con estos discursos y prácticas tecnocientíficos para la producción de café, en la cotidianidad ponen en acción prácticas y conocimientos que vinculan lo transferido con sus experiencias particulares (cf. de Certeau, 2000). Por ejemplo la FNC promociona la renovación de los cultivos cada cuatro o cinco años, y el uso de semillas certificadas como variedades Castillo y Cenicafé1, para remplazar variedades anteriores como la variedad Colombia $^{23}$, sin embargo en la actualidad se pueden encontrar fincas donde los caficultores a pesar de las instrucciones impartidas por los

que no manejan el lenguaje técnico y se constituyen en una herramienta clave del servicio de extensión.

${ }^{22}$ Enfermedad ocasionada por el hongo Colletotrichum Kahawae, que afecta todos los estados de los frutos de la planta de café, desde la floración hasta las cerezas maduras (Gil, Cárdenas y Gómez, 2000).

${ }^{23}$ La Variedad Colombia es una semilla resultado de un proceso de investigación para afrontar la roya que inició en los años 1960, y que en 1980 fue entregada en Cenicafé, y se constituye en la primer "variedad mejorada de café" implementada en Colombia (Moreno y Alvarado: 2000:8). 
extensionistas, siguen manteniendo viejos cafetales de variedad Colombia por considerarlos muy resistente, pues en la crisis ocasionada por la roya (periodo 2010-2011), fueron los cafetales que sobrevivieron; lo mismo ocurre con cafetos de arábiga que aún se mantienen en los cafetales por considerarlos de mejor calidad, ser más resistente a largo plazo y tener mejor sabor. En cuanto a la renovación, algunos caficultores no la realizan en los tiempos estipulados, ya que consideran en primer lugar, que los cafetales aún tienen posibilidades de producir y, en segundo lugar, por los costos que esto genera y el tiempo que deben esperar, de dos a tres años, para que el café comience a producir, razón por la cual deciden prolongar los tiempos para la renovación de los mismos.

Si bien la construcción de los semilleros o germinadores es una práctica estandarizada por la FNC, en algunas de las fincas de Palmor encontramos una diversidad de dinámicas y prácticas que no siempre tienen como principal soporte los conocimientos técnicos, dado que aquí toman lugar otros factores como las relaciones sociales, el escepticismo, los conocimientos llamados empíricos y los heredados de padres o abuelos, lo cuales reconfiguran los procesos técnicos en torno a la producción de café. De este modo encontramos caficultores que construyen semilleros, pero sin seguir las normas expuestas en el Manual del Cafetero o en los boletines técnicos, sino a partir de sus conocimientos o por recomendaciones de personas allegadas que han visto resultados adecuados con la implementación de prácticas específicas o la siembra de semillas traídas de otros países. Por otra parte, muchos de los caficultores consideran que esta es una actividad complicada y de mucho cuidado, por lo cual no todos construyen germinadores y prefieren comprar las chapolas ${ }^{24}$ listas para la elaboración del almácigo ${ }^{25}$. Esto supone, además, una suerte

\footnotetext{
${ }^{24}$ Plántula de café de pocas semanas de germinación a partir de la cual se hace el almácigo.

${ }^{25}$ La chapola de café se trasplanta en una bolsa plásticas para que termine su desarrollo antes de ser ubicada sobre
}

de mercado de plántulas de café o chapolas entre los caficultores.

Es preciso mencionar que la compra y venta de chapolas no se limita a corregimientos o municipios en particular, si no que puede extenderse a diversos puntos de la SNSM y los extensionistas pueden encargarse de facilitar la conexión entre productores. No obstante, la compra y venta de semillas y chapolas se da principalmente mediante las redes que se establecen entre los caficultores tras formar parte de asociaciones y cooperativas en común u otro tipo de redes sociales locales de parentesco y amistad. Por ejemplo, durante el trabajo de campo realizado en Río Piedras se pudo observar que algunos de los caficultores de esta zona compran las chapolas o semillas a productores de Palmor; mientras que en este último hay caficultores que traen semillas de la región andina o de otros países como Costa Rica; estos caficultores hacen uso de sus conexiones personales para importar las semillas. En Palmor algunos productores han comenzado a sembrar un tipo de café que denominan "de porte bajo", debido a que no crece mucho, pero tiene una gran producción y logran alta valoración en las pruebas de taza; esta variedad de café al no estar certificada por Cenicafé, los extensionistas no recomiendan sembrarla y advierten que estas plantas pueden ser susceptibles a la roya, lo cual da lugar a posibles pérdidas económicas. No obstante, esto no es impedimento para su siembra, pues muchos productores, como Luis Arias $^{26}$, caficultor joven de Palmor, menciona haber conocido de primera mano el desarrollo y producción de esta semilla en fincas de caficultores conocidos y tiene plena confianza de la viabilidad de la misma, lo que lo ha llevado a entrar en debate con el extensionista del distrito, pues considera que sus conocimientos sobre este tipo de café son resultado de su experiencia de vida y no se limita a teorías desarrolladas en

el terreno final. En esta fase la planta y el sustrato que la mantiene se denomina almácigo.

26 En comunicación personal con Luis Arias, el 27 de marzo de 2017 en Palmor. 
laboratorios, enfatizando que su conocimiento sobre el café es de toda la vida, heredado de familiares y allegados, por lo que en suma son muchos años de conocimiento que le permiten tomar decisiones con criterios firmes $y$ sustentados. Inclusive, productores con pocos años de experiencia, se asocian con otros caficultores amigos o allegados que llevan muchos años en el cultivo del café con quienes intercambian información. Por otro lado, hay una gran cantidad de productores que prefieren comprar las semillas directamente al Comité Departamental de Cafeteros, pues para ellos las variedades producidas por Cenicafé tienen la fortaleza de ser resistentes a la roya, enfermedad que afectó a un gran porcentaje de cafetales de variedades Arábiga y Caturra.

De igual forma, se pudo apreciar que algunos caficultores se muestran escépticos ante ciertos avances científicos generados por Cenicafé y promovidos por los extensionistas, como el caso de última variedad de café producida por la FNC,
Cenicafé1, pues varios productores a la hora de recibir la recomendación para su siembra plantean que "hasta no ver no creer", refiriéndose a las cualidades de la planta, de la cual se promete una gran producción, baja altura, gran sabor de taza y resistencia a diversas enfermedades, entre ellas la enfermedad de la cereza del café (CBD). Debido a esto algunos productores sugirieron a los extensionistas la realización de una gira a las parcelas experimentales de Cenicafé en Chinchiná (Caldas, centro del país) con el fin de corroborar las bondades de la nueva semilla. No obstante, es probable que la FNC propicie la creación de semilleros y parcelas experimentales en fincas seleccionadas, como ha ocurrido en experiencias previas donde la FNC aporta la semilla y junto con los extensionistas se construye el semillero; esta actividad se realiza a modo de capacitación, por lo cual los productores del distrito donde se encuentra el cultivo experimental son invitados a conocer el proceso (Fig. 3).

Figura 3. Construcción de Semillero Experimental variedad Cenicafé1, Finca La Unión, Vereda El Boqueron, Distrito Río Piedras.



Fuente: Mirleydis De La Hoz Montes. 


\section{Almácigo}

El almacigo consiste en el establecimiento de un espacio idóneo en el que las chapolas o plántulas que se producen en el semillero puedan convertirse en plantas fuertes por lo general en bolsas plásticas especiales, para posteriormente ser trasplantadas en el terreno definitivo. El proceso consiste en seleccionar las mejores plántulas para garantizar su desarrollo, producción y longevidad (Fig. 4).

Para el establecimiento de los almácigos la FNC recomienda el uso de bolsas con capacidad de 1 o 2 kilos, dependiendo del tiempo que tomará hasta el trasplante. De igual forma se debe controlar la arvense, hongos, microorganismos y la nutrición. Para este proceso algunos productores contratan a personas o trabajadores de la región o de otros lugares con experiencia en elaboración de almácigos, para que se encarguen de escoger el sustrato, llenar las bolsas y sembrar las chapolas, pues estas son labores meticulosas y demandantes debido a que el número de plantas a sembrar puede superar los miles, sin contar que se debe tener cuidado a la hora de sembrar la planta para que la raíz no sufra daños y controlar la cantidad de abono necesario por bolsa.

Otros caficultores prefieren liderar ellos mismos el proceso de siembra en bolsa, con el propósito de garantizar que se cumpla con el "mejor" método para hacerlo, el cual aprendieron durante las capacitaciones impartidas por la FNC; por lo general estos productores tienden a estar en contacto -vía telefonía celular- con el extensionista para consultar sobre las dudas que se puedan presentar durante el proceso o para solicitar su visita para la revisión del almacigo.

Figura. 4. Almacigo, Finca del Señor Siervo de Dios, Palmor

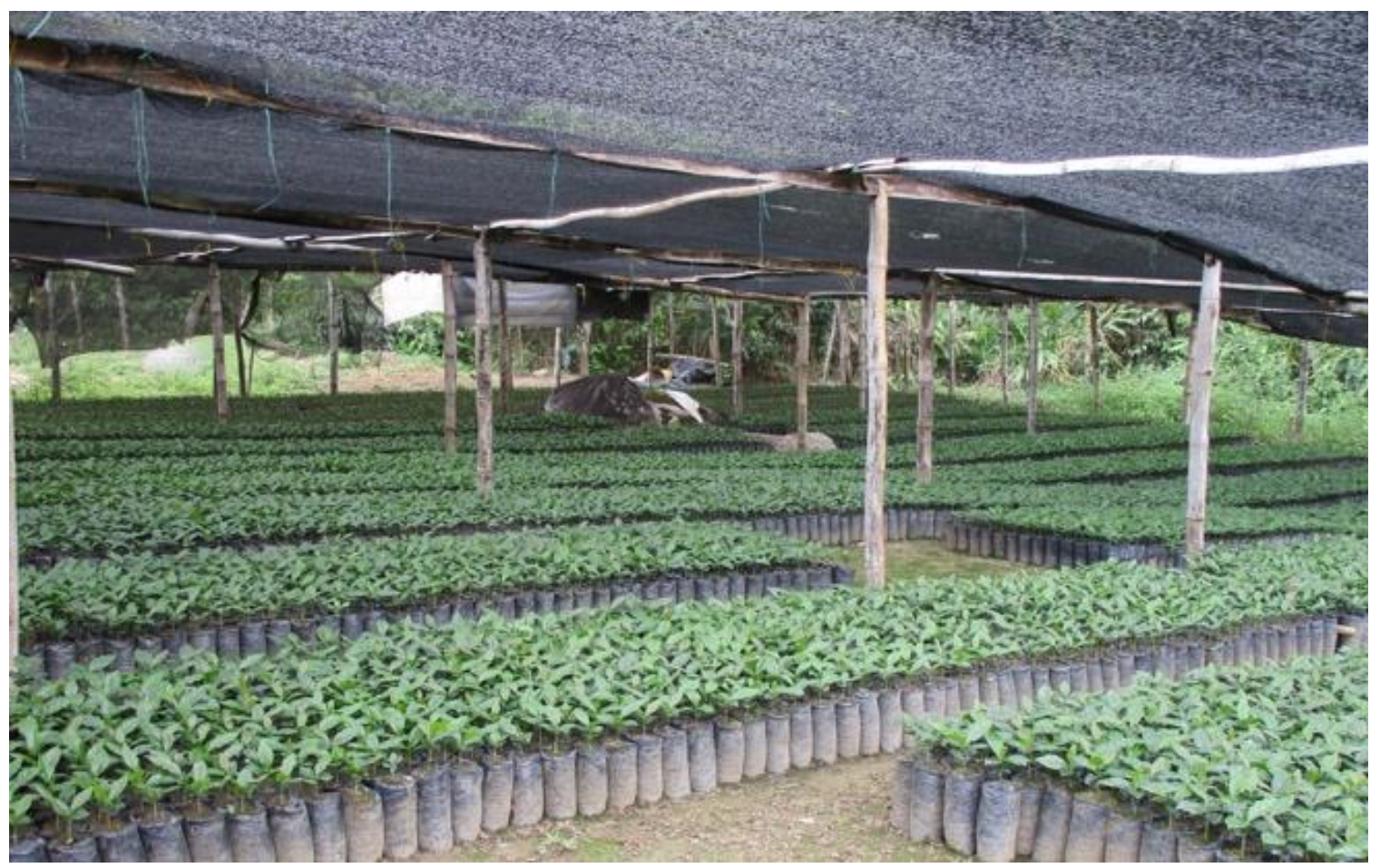

Fuente: Mirleydis De La Hoz Montes, 28 de marzo de 2017

Sin embargo, durante el trabajo de campo, también, fue posible escuchar quejas de los extensionistas respecto a que los caficultores no siguen las instrucciones dadas por ellos, principalmente en relación con el tamaño de las bolsas que se deben usar o sobre el cuidado que 
se debe tener para evitar la proliferación de hongos o enfermedades, lo cual en ocasiones genera pérdidas para los caficultores ya que se deben descartar muchas plantas. De igual forma se pudo evidenciar que no todos los productores están dispuestos a desechar chapolas con defectos en las raíces y proceden a trasplantarlas en los lotes.

\section{Establecimiento de cafetales}

De acuerdo con las normas establecidas por Cenicafé, el establecimiento de los cafetales debe seguir ciertas recomendaciones técnicas, para lo cual se debe tener en cuenta aspectos como el clima, suelos, precipitaciones, altura y luminosidad. A partir de estos aspectos se define el tipo de sistema de producción agrícola para la siembra de los cafetales (sistema agroforestal, sistema silvopastoril, cortina rompe vientos, plantaciones con linderos de árboles) (FNCCenicafé, 2013a). La SNSM debido a sus condiciones geográficas y climáticas presenta una época de verano muy intensa entre enero y abril y una alta exposición al sol, lo que puede incrementar el estrés en las plantas, lo cual puede afectar la producción e incluso, la perdida completa de cafetales. De acuerdo con la FNC, los cafetales no pueden estar expuestos al sol de forma directa, por lo cual se recomienda a los caficultores implementar sistemas agroforestales que cumplan la función de dar sombra y regular el clima (Fig. 5), lo cual coincide con las prácticas que varios caficultores heredaron de sus padres.

Figura 5. Cafetal con sombrío, finca Atinkana, Río Piedras.



Fuente: Mirleydis De La Hoz Montes. 9 de febrero de 2017.

En los dos distritos cafeteros de este estudio, los caficultores mencionan que el establecimiento de sombrío es la única manera de poder producir café en la SNSM. El guamo (Inga sp.), árbol nativo, es la especie para sombrío que más se utiliza en estos dos distritos cafeteros, dado que hace parte de los conocimientos y prácticas "tradicionales" de los caficultores (Monsalve, 1927), resultado de la experiencia que traían de otras zonas cafeteras los primeros productores que se asentaron en esta zona del macizo montañoso, como lo hace visible el extensionista Alex Saurith, al considerar que "las mismas condiciones de la Sierra, la oferta ambiental, te 
dice que tienes que tener sombra; y los [personas] antiguos, los cafeteros siempre han manejado el sombrío. ¿Que lo han manejado inadecuadamente? Ya ahí, entramos nosotros"27. En tal sentido la práctica del sombrío no fue establecida por FNC, pero si entra a ser regulada por ellos bajo parámetros tecnocientíficos.

Por ejemplo, al dialogar con algunos caficultores, se pudo evidenciar que no necesariamente el sombrío fue incorporado como algo planificado, o por cumplir con los criterios establecidos en el Manual cafetero, pues los árboles, generalmente guamo y en menor medida otras especies, que acompañan los cafetales de sus fincas, no fueron parte de un proceso predeterminado, sino que estos crecieron porque en el sector habían quedado semillas de esta especie la cual ofrece una sombra adecuada. A pesar de las recomendaciones en otros sectores, se puede observar cafetales que se encuentran en las laderas, con exposición directa al sol y al viendo, que no cuentan con sombrío.

En zonas como Río Piedras, se está comenzando a sembrar aguacate asociado al cultivo de café para proporcionarle sombra a este, lo cual a su vez genera nuevos ingresos, dado que, durante el trabajo de campo, fue posible escuchar a los caficultores quejarse sobre los bajos precios del café y la necesidad de buscar alternativas para suplir las necesidades y gastos de mantenimiento de los cafetales. Es importante anotar que esta idea es producto de proyectos de organizaciones diferentes a la FNC, aunque esta última también promueve estas alternativas de diversificación.

Además del guamo, del aguacate y el plátano, que se usan para sombrío, alimentación y

${ }^{27}$ En comunicación personal con Alex Saurith el 17 de marzo de 2017.

${ }^{28}$ Productor considerado por el Comité Departamental de Cafeteros del Magdalena como un "modelo a seguir", pues en poco tiempo ha logrado incrementar su producción y hacer de su finca una empresa cafetera sostenible, contar con marca de café propia, silo industrial, en el que presta comercialización, los caficultores siembran en sus parcelas cultivos como yuca, malanga, maíz, entre otros, los cuales son utilizados, principalmente, para el autoconsumo y complementar la comida de los trabajadores de la finca; aun cuando esta es una práctica que ha estado vigente desde que inició la migración de población del interior del país, la FNC - a partir diferentes talleres y cursos- enfatiza en la necesidad de producir junto con el café, cultivos asociados como una manera de aminorar gastos o generar nuevos ingresos, bajo la idea de finca como empresa cafetera, impulsada desde los programas de gestión empresarial, aunque los policultivos son propios de las prácticas agrícolas de caficultores en esta región y otras de Colombia (Sánchez-Clavijo, Botero-Echeverri y Vélez, 2007).

Por otro lado, la regulación de la sombra es usada también como modo de control de plagas o enfermedades, dado que muchas enfermedades del café como la gotera y la mancha de hierro, pueden reducir sus efectos al disminuir o aumentar la sombra de un cafetal. El tipo de sombra que se utiliza, también se encuentra asociado a diferentes prácticas como la producción de cafés especiales, dado que algunas características del café, como el sabor y el aroma, dependen de las condiciones del suelo, el clima y los cultivos asociados (Gamboa, Mosquera y Paz, 2013) generando diferentes perfiles de taza (SCAN, 2015) agregando valor al café.

En Palmor fue posible encontrarnos con un caso particular, en el que el productor que lleva aproximadamente seis años a cargo de su finca, Guillermo Flórez ${ }^{28}$, quien hace parte del empalme generacional $^{29}$, ya que de sus padres

el servicio de secado mecánico de café a la comunidad y una bodega de almacenamiento de café para compra y venta del mismo.

29 Anteriormente se denominaba relevo generacional, sin embargo, luego de ser discutido en el Primer Foro Mundial de Productores de Café desarrollado en MedellínColombia, los días 10-12 de julio de 2017, el término se 
heredó la cultura cafetera, ha establecido diferentes tipos de cafetales experimentales con el fin de evaluar las prácticas que le sean más efectivas en términos económicos, para ello ha implementado tres tipos de cultivo de café establecidos bajo el sistema agroforestal: uno bajo los conocimientos y técnicas definidas por FNC, otro en el que experimenta con conocimientos que ha obtenido mediante viajes y experiencias en fincas de diferentes partes de Colombia, y en otros lotes integra conocimientos propios y los transferidos por la FNC. En el lote donde experimenta con conocimientos adquiridos en otras localidades, el café lo cultiva asociado a árboles de naranjo, con el propósito de generar un café con tonalidades cítricas en su sabor y aroma, mientras que en otro lote el café se cultiva asociado a plantas de plátano y fríjol (Fig. 6). Este proceso de experimentación emprendido por este joven caficultor, es parte de la apuesta que él ha generado, ya que plantea que no se debe quedar sólo con los conocimientos que la FNC le transfiere, sino que él se preocupa por conocer otras formas de producir café, viéndose en la necesidad de experimentar con esos nuevos conocimientos en su finca para hacerla más rentable.

\section{Figura 6. Cafetales finca Guillermo Flórez, Palmor (Ciénaga- Santa Marta)}

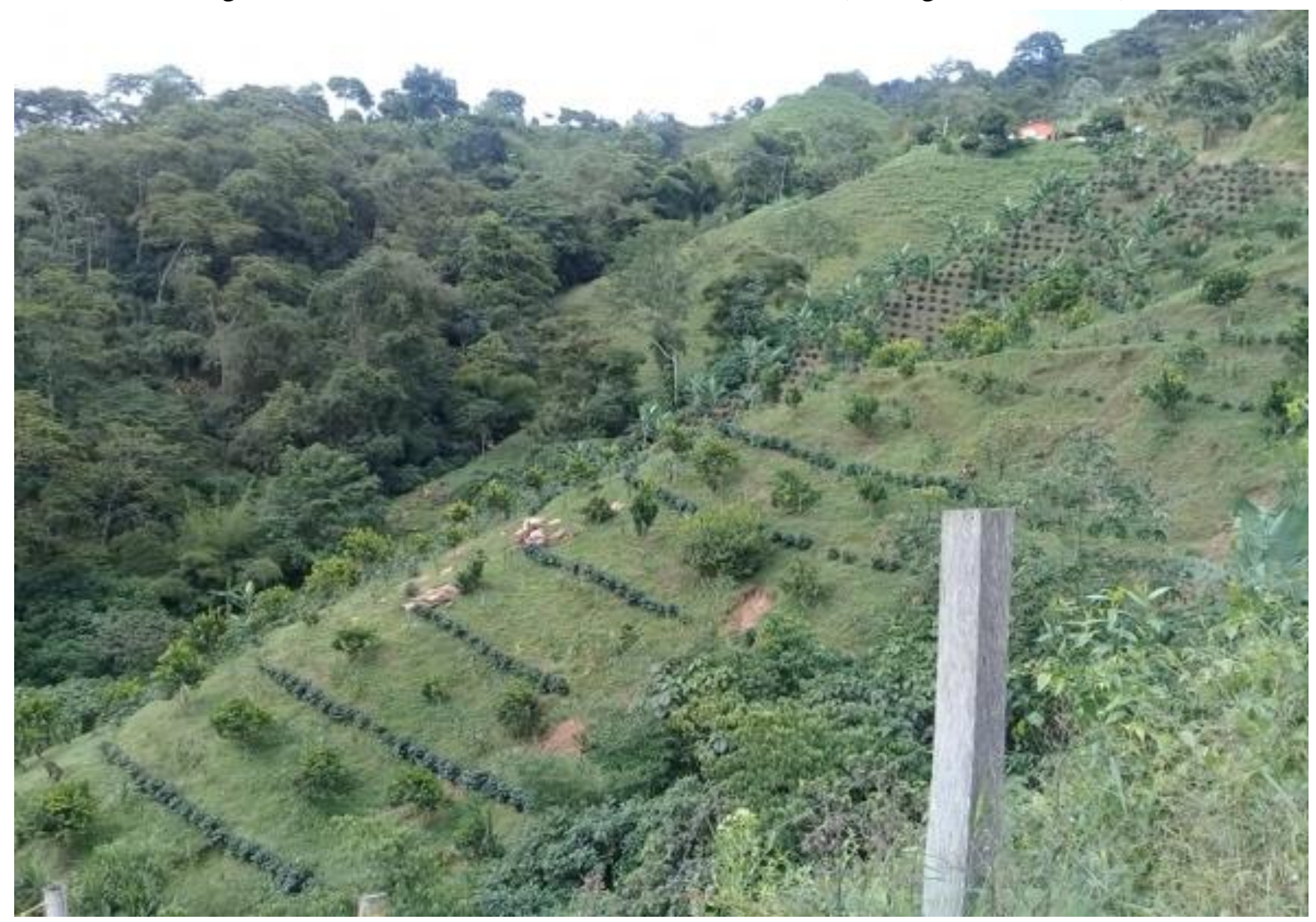

Fuente: Mirleydis De La Hoz Montes.6 de octubre de 2017.

cambió por empalme generacional, ya que se entiende que los hijos de una familia cafetera continúan con la administración de la finca con el apoyo y guía de sus padres. 
Los jóvenes se han constituido en un actor clave, ya que por ejemplo, el acceso a la educación académica, incluso el hecho de saber leer y escribir, supone conocer otras realidades, así como el acceso a la información gracias a las nuevas tecnologías de la comunicación y la conectividad por carretera, les ha permitido a algunos viajar por el país conociendo otras experiencias asociadas al cultivo de café, a otros grabar en sus teléfonos celulares las instrucciones dadas por los extensionistas, a otros estar informados sobre el precio de café en la bolsa de valores de Nueva York y a otros criticar algunas instituciones del Estado por la forma como gestiona el comercio del café.

De esta manera, el arreglo de los cultivos da cuenta de las transformaciones, no sólo técnicas, sino también sociales, en la medida en que a través de prácticas específicas y factores "externos" al cultivo de café se conectan, transforman y reconfiguran los modos de vida de los caficultores de Río Piedras y de Palmor. En este sentido una finca cafetera es el resultado de múltiples dinámicas sociomateriales, que implican desde factores socio-políticos, hasta aspectos bio-físicos, que generan procesos particulares en los cuales se genera nuevo conocimiento, sobre el café, la finca y el territorio.

\section{Mantenimiento de cultivos}

En el Manual del Cafetero se presenta todo un paquete tecnológico para el mantenimiento de los cultivos de café, el cual está orientado a la nutrición de los cafetales, el manejo de la arvense y el control de enfermedades y plagas del café. Los cafetos se entienden como seres vivos que requieren nutrirse para su desarrollo, crecimiento y producción ${ }^{30}$ (FNC-Cenicafé,

\footnotetext{
${ }^{30}$ Los elementos químicos requeridos por las plantas de café están divididos en dos grupos: 1. los constituyentes orgánicos: hidrogeno, carbono y oxígeno, los cuales son tomados del agua y la atmosfera; 2. los nutrientes, que se encuentran en el suelo y según los requerimientos de las
}

2013b:88). De este modo, la principal herramienta que se ha establecido desde la FNC para lograr lo anterior es el análisis de suelo, práctica tecnocientífica en la que, por medio pruebas de laboratorio, se analizan las características químicas de muestras de suelo de los cafetales. Los resultados permitirán determinar la cantidad y el tipo de nutrientes (abono) que se debe aplicar a cada planta de café para garantizar el éxito en la producción.

El manejo integral del arvense que consiste en el control de ciertas plantas que crecen asociadas al café, (FNC-Cenicafé, 2013b) para mantener el equilibrio ecológico entre el suelo, las fuentes de agua y el café sin afectar el crecimiento de los cafetos. El proceso de "limpia" (deshierbe) puede realizarse de manera manual, mecánica (machete, azadón, moto-guadañadora) o química (herbicidas). En cuanto a enfermedades y plagas del café (FNC-Cenicafé, 2013b) se busca controlar factores bióticos, asociados prácticas agronómicas desfavorables, por ejemplo, inadecuada nutrición de las plantas o sombrío, plantas susceptibles a enfermedades, presencia de patógenos, ya sean hongos, bacterias, virus, fitoplasmas o nematodos; o abióticos, causados por elementos del entorno como el granizo (FNC-Cenicafé, 2013b).

En el año 2010 y 2011, la roya afectó los cafetales en los distritos cafeteros de Palmor y Río Piedras, lo que favoreció que muchos productores renovaran los cafetales enfermos y decidieran sembrar nuevas semillas ofertadas por la FNC, se vincularan en programas de créditos, de transferencia de tecnologías, de gestión empresarial, entre otros, con lo que generaron nuevas dinámicas en las fincas cafeteras. No obstante, algunos caficultores no eliminaron completamente los arbustos de la

plantas se subdividen en macronutrientes: nitrógeno, potasio, calcio, fosforo, magnesio y azufre; $\mathrm{y}$ micronutrientes: hierro, manganeso, cobre, cinc, boro, cloro, molibdeno y níquel. 
variedad arábiga y actualmente son plantas productivas consideradas de mejor calidad.

Por otro lado, con respecto al control de plagas del café, FNC (FNC-Cenicafé,2013b), al igual que lo hace con las enfermedades, realiza una descripción de los insectos que atacan los cultivos, desplegando toda una variedad de recomendaciones que pueden ser usadas de acuerdo con la especie que se desee controlar, entre ellas la broca (hypothenemus hampei), un pequeño coleóptero que se alimenta de los frutos del café. El principal método de control que se tiene en estas zonas es el llamado rere (repasa y recoge), que consiste en recolectar minuciosamente todos los frutos, especialmente los afectados con el fin de evitar la proliferación de este insecto. Uno de los métodos recomendados por la FNC, en casos extremos, es la aplicación de plaguicidas por medio de aspersión, sin embargo, tanto en Río Piedras como en Palmor, este es el último método que los caficultores consideran implementar y por lo general se realiza cuando otros métodos no han funcionado. Esto está asociado a que los caficultores consideran que el uso de biosidas trae graves perjuicios a largo plazo para la salud humana, juzgándose que la solución, uso de venenos, es más costosa que el problema; es por esto que el rere es una actividad muy importante para los productores.

Las prácticas de mantenimiento de cafetales inician desde que se establece el semillero, dado que se debe tener control de las plagas y enfermedades del café en esta etapa; durante el almacigo se debe iniciar un proceso de nutrición de las plantas, de control de plagas y enfermedades y el establecimiento de un microclima que sea óptimo para el desarrollo y crecimiento de las chapolas, es en esta etapa que algunos productores tienden a contactar a los extensionistas, pues si alguno de estos procesos no se realiza con rigurosidad es muy probable que se deba desechar parte de las plantas antes de ser trasplantadas en los lotes.
No obstante, durante el trabajo de campo fue posible conocer caficultores que implementan las prácticas mencionadas haciendo ajustes según su experiencia y conocimientos y no exactamente como le indica el extensionista o el manual cafetero, dado que su implementación implica realizar inversiones que los productores no siempre están en condiciones de hacer. Por ejemplo, en Palmor fue posible conversar con un caficultor que nos explicaba que él hacía "las limpias" teniendo en cuenta las recomendaciones que el extensionista le hacía, pero no cortando las arvenses con las medidas exactas, puesto que esto le incrementaba los jornales a pagar por esta actividad, ya que la recomendación es cortar la arvense a 20 centímetros del suelo para proteger este último, sin embargo él lo hacía a 10 centímetros, puesto que consideraba que aun así lo protegía y las limpias las realizaba con menor frecuencia, reduciendo de esta manera los gastos y haciéndolo sostenible para su economía doméstica. La inversión en insumos y maquinaria surge como una problemática común a muchos caficultores; por ejemplo, en Río Piedras un productor aseguraba que su deseo era contar con las maquinarias e insumos que le permitieran llevar un proceso bajo los estándares de FNC, e inclusive llevarlo hasta etapas más avanzadas de transformación, como el tostado; sin embargo, asegura que su gran limitante es que el retorno que tienen en ganancias no permite hacer la inversión necesaria para optimizar las etapas del cultivo y transformación. De este modo las dinámicas comerciales que definen el precio del café en grano se constituyen en un factor que determina los procesos de apropiación de los sistemas tecnológicos transferidos por la FNC.

Para el gremio de caficultores y en especial en los productores orgánicos, se considera que las actividades de mantenimiento de los cultivos de café deben ser lo menos dañinas posible para los humanos y el medio ambiente, por esto, desde las asociaciones de productores orgánicos, se realiza control y seguimiento a las fincas 
asociadas $\mathrm{y}$ certificadas. Al respecto un caficultor que habita en el Palmor, hizo énfasis que en su finca sólo usaba abonos orgánicos elaborados por él a partir del procesamiento de la pulpa del café y estiércol de gallinas (gallinaza). Pero en este caso en particular, la iniciativa de ser productor orgánico de café surgió como respuesta para resolver situaciones concretas que no le permitían obtener los agroquímicos necesarios para el cultivo de café y debió optar por el uso de la gallinaza como una posibilidad para nutrir las plantas. Una vez incorpora los abonos orgánicos y siguiendo las recomendaciones del análisis de suelo realizado por la FNC el caficultor menciona que "trato de echarle suficiente o digo que suficiente o de pronto no es tan suficiente porque a uno lo que le recomienda es echarle un kilo a cada mata y dos veces al año y yo de pronto le echaré una libra" 31 . En esta medida se puede apreciar que los productores, de acuerdo con sus condiciones socioeconómicas, políticas y sus conocimientos implementan de diversas maneras los discursos y prácticas tecnocientíficas en la producción de café, sin embargo constantemente las están ajustando, redefiniendo y negociando; y aunque algunos indican obviar muchas de las recomendaciones que le dan los extensionistas y supervisores de la FNC y de las asociaciones de café, al considerar que no las requieren ya que saben cómo hacer su trabajo, no se "pierden" el programa de televisión de la FNC, El Profesor Yarumo, implementan estrategias para el secado de café, como la construcción de marquesinas, sistema para la filtración de aguas mieles para evitar la contaminación de las corrientes de aguas, solo por mencionar algunas. En general se desarrollan prácticas que permiten continuar como productor orgánico. De este modo, se evidencia más que una no aceptación de estos conocimientos y prácticas, una reconfiguración de los mismos, puesto que son ajustados de acuerdo al modo de ser de los caficultores, a partir de lo cual se da una "naturalización" o interiorización de los sistemas tecnológicos, en la que muchas de las prácticas tecnocientíficas han entrado a formar parte de su modo de vida, de su cotidianidad, haciéndose difusa la línea que separa los conocimientos tenocientíficos de los tradicionales. Con cada dinámica asociada a la producción del café se evidencia lo heterogéneo y rico de los procesos de apropiación de la ciencia y la tecnología y en general de generación de conocimiento en este espacio que llamamos finca cafetera.

\section{Cosecha del café}

La cosecha es el proceso de recolección de los frutos maduros del café, la cual en Colombia se realiza principalmente de manera manual. En el Manual del Cafetero, se detalla cómo se debe realizar la recolección, especificando los movimientos y micro-movimientos que debe hacer para arrancar los frutos, con el fin de hacer el proceso más rápido y efectivo. De igual forma se promociona el uso de dispositivos (e.g. mangas) especiales para la recolección de café.

Sin embargo, al charlar con los productores de las regiones estudiadas, algunos de ellos mencionaron no hacer uso de estas técnicas, debido a que ellos saben cómo realizar esta actividad, lo cual han aprendido a través de la experiencia y las enseñanzas de sus padres. En algún momento la FNC le recomendó a los caficultores utilizar un dispositivo especial para la recolección de café, que consistían en unas mangas o canguaro, conductos fabricados en tejido sintético, para colocarse en las manos para depositar directamente los granos retirados de las ramas del cafeto. Ante esta iniciativa los productores con los que conversamos nos manifestaron que no lo vieron como una opción, puesto que para ellos era más trabajo, por tanto, continuaron con el proceso de recolección que traían (manual con recipiente atado a la cintura para depositar los granos). Los productores de los dos distritos cafeteros, en muchos casos contratan a recolectores de la región o de otras partes del país para que realicen esta actividad, y con el fin de que durante el proceso recolección

\footnotetext{
${ }^{31}$ En comunicación personal, El Palmor, 2017.
} 
no dañen las plantas, arranquen o partan sus hojas y/o ramas algunos de los caficultores y familiares supervisan este proceso. Los recolectores en general no cuentan con formación académica, sin embargo, algunos han realizado estudios en el SENA, han recibido capacitaciones por parte de la FNC o de diferentes instituciones en labores concernientes a los procesos de cultivo del café, o prácticas agronómicas en general e incluso en la construcción de herramientas. Por lo general, estas personas son contratadas por recomendación, es decir que los productores tienden a preguntarse entre sí sobre qué persona podría cumplir ciertas labores en sus fincas.

Por otro lado, el tiempo de cosecha en la SNSM, por lo general, está acompañado por fuertes lluvias, lo que en muchas ocasiones supone dificultades para los productores, dado que con las lluvias los frutos del café tienden a caerse y perderse, por ello, si las lluvias no cesan, los productores suelen contratar más personal para recoger el café, incluso sin hacer mayores distinciones entre frutos maduros o inmaduros, la selección de los frutos se hace posteriormente durante el beneficiado ${ }^{32}$. Algunos productores aseguraron que en la actualidad no cuentan con un método propio para pronosticar el clima y así planear las actividades del cultivo, puesto que consideran que desde hace 20 años el clima les es más incierto, en la medida que las épocas secas y de lluvia no se dan en los tiempos adecuados, y en algunos casos se traslapan, pues se pueden presentar lluvias frecuentes en épocas de verano o fuertes oleadas de calor durante la época de lluvias, por lo cual los productores prefieren seguir las recomendaciones del extensionista, haciendo uso principalmente del registro de la floración para determinar, por ejemplo, los tiempos de la cosecha; esto entonces se constituye en un factor que influye en la implementación y apropiación de los sistemas tecnológicos transferidos por la FNC.

\footnotetext{
${ }^{32}$ Proceso que consiste en despulpar el grano, fermentarlo durante un tiempo determinado para desprender el mucilago y posteriormente lavarlo y secarlo.
}

\section{Discusión y conclusiones}

Cuando presentamos esta propuesta de investigación al Comité Departamental de Cafeteros del Magdalena, sus directivos encontraron gran pertinencia en el asunto, dado que la apropiación de las tecnologías transferidas es una de sus actuales preocupaciones y la FNC no cuenta con un método que les permita evaluarlo, por lo cual recurren a la calidad del producto final como la forma de identificar la adopción de tecnologías. En este mismo sentido estudios realizados en México, Perú y Ruanda se han enfocado en la transferencia, monitoreo y evaluación de la adopción de los conocimientos y prácticas agrícolas en la producción de café (Gathani, Gómez, Sabates y Stoelinga, 2016; Moreno-Seceña, Nava-Tablada y HernándezSánchez, 2015; Zapata y Marín, 2015) haciendo evidente las dificultades de evaluar los procesos de adopción de tecnologías y conocimientos. En Colombia la ASCyT es una preocupación de los programas de desarrollo en general (Colciencias, 2010b), que ha dado lugar a diversas discusiones (Daza-Caicedo et al. (2017; Domínguez, Echeverry y Castaño, 2013; Lozano-Borda, Pérez-Bustos y Roatta-Acevedo, 2012; PérezBustos, 2010) para explorar modelos de apropiación que generen procesos que articulen los conocimientos y prácticas tecnocientíficos y otras formas de ser y entender el mundo. Para el caso de este trabajo, la ASCyT la hemos entendido como un proceso que se genera posterior a la fase de transferencia e implica una negociación que da origen a nuevos ensamblados tecno-sociales (cf. Restrepo, 2013); en este sentido, a la hora de estudiar los procesos de apropiación de las tecnologías transferidas por la FNC en los municipios Ciénaga y Santa Marta, fue pertinente identificar los actores implicados y sus realidades, los sistemas tecnológicos y los modos en que es entendido el café y lo que involucra para cada 
uno de los actores en sus redes sociomateriales específicas.

En el cultivo del café encontramos una gran diversidad de actores humanos y no humanos configurando las diferentes etapas del proceso de producción, sin embargo, aquí nos referiremos principalmente a dos: el caficultor y el extensionista, ambos sujetos activos que representan mundos particulares, que a su vez están interconectados con otros mundos, los cuales suponen más actores, dispositivos y modos de vivir el café. De esta manera, para entender las formas de intra-acción e interacción de los caficultores de Río Piedras y de Palmor frente a los conocimientos transferidos por la FNC, es pertinente tener en cuenta sus historias de vida y sus formas particulares de entender y habitar el mundo, puesto que esto define las maneras de intra-actuar con el café y el modo en que lo viven; por otra parte, a la hora de ver al extensionista, lo vemos como un actor que hace parte de un dispositivo enorme de producción y transferencia de conocimiento, quien articula la institucionalidad cafetera, unos conocimientos tecnocientíficos y dinámicas globales de mercado, con los procesos locales que interviene. En este sentido, en el momento en que estos dos actores se encuentran, no sólo lo hacen dos personas sino toda una diversidad de conocimientos, prácticas y seres que han sido el resultado de intra-acciones e interacciones históricas en condiciones sociomateriales específicas (cf. Martínez-Dueñas y Perafán, 2017; Perafán y Martínez-Dueñas, 2016; Martínez-Dueñas, 2016; Vargas, Palacios, Ocampo y Aguilar, 2017; Bortz, 2017; Tocancipá-Falla, Perafán y Martínez-Dueñas, 2016).

Por otro lado, en este encuentro también hacen presencia diversos factores que influyen en la manera cómo estos dos actores pueden relacionarse y por ende en los modos cómo los sistemas tecnológicos transferidos son

33 Para una revisión sobre estudios que abordan la multidimencionalidad de factores que históricamente apropiados: desde las relaciones intersubjetivas entre el técnico y el productor, hasta el precio del grano en los mercados internacionales, pasando por aspectos climáticos, económicos y políticos $^{33}$.

Esto es un proceso que ocurre a todo lo largo de la producción y comercialización del grano, donde el extensionista y el productor se articulan a dispositivos de intervención diseñados para cada etapa del cultivo, dentro de los que podemos resaltar dos de ellos: las semillas mejoradas de café y el análisis del suelo. El primero es un dispositivo con el que se pretende iniciar el proceso de transformación de los cultivos, y ha sido desarrollado para resistir ciertas enfermedades y plagas del café y aumentar la producción y calidad del mismo, por lo que está directamente ligado a las dinámicas del mercado, en las que se encuentra inmersa Colombia como productor y exportador de café a nivel mundial, y la idea de ver la finca como empresa cafetera, a partir de la cual se transforman los modos de administrar la producción del café; esta semilla llega a la finca con todo un paquete de conocimientos, procedimientos e insumos agrícolas. De igual modo, el análisis de suelo como dispositivo de intervención, más que de evaluación, está diseñado para regular los cultivos y por extensión la finca y se constituye en una puerta que se abre para dar paso a una diversidad de prácticas tecnocientíficas con las que se pretende la optimización de la nutrición de las plantas, el control de arvense y manejo de plagas y enfermedades del café.

Al igual que el extensionista, el caficultor de la SNSM está acompañado de toda una historia de relaciones y experiencias en torno al café, vivencias atravesadas por el conflicto armado, el destierro, las bonanzas, las crisis económicas y la búsqueda del progreso; lo cual determina los procesos de producción de conocimiento articulando su experiencia con otros actores,

determinan las dinámicas campesinas ver TocancipáFalla, Perafán y Martínez-Dueñas (2016). 
eventos y dinámicas en el vivir, es decir, que los cultivos de café se configuran a partir de situaciones históricamente situadas (Blaser, 2009) y los modos en que los caficultores afrontan tales situaciones, haciendo de la finca un espacio de producción de conocimiento.

Es importante mencionar que el flujo de conocimientos y mercancías con los que interactúa el caficultor actualmente, dan lugar a reconfiguraciones y modulaciones (Lazzarato, 2006) de su relación con el café, permitiendo la pluralización del caficultor como actor y dando paso, en primer lugar, a un caficultor que apela al conocimiento "tradicional" 34 , es decir a sus conocimientos, prácticas y modos de vida heredados, quien mira con desconfianza las nuevas tecnologías presentadas por el extensionista, pero que las ha venido implementado de diferentes maneras en el proceso de producción de café, y que en algunos casos se han naturalizado como tradicionales, pero que al enfrentarse con factores que salen de su control como el cambio climático, el desgaste de los suelos y las crisis económicas por el bajo precio del café en los mercados internacionales, puede generar transformaciones en sus prácticas, sin embargo conserva una visión particular y nostálgica de su finca. En segundo lugar, se observa un caficultor empresario, donde el café es visto como medio para generar recursos económicos, aquí la forma de vivir la finca cafetera se transforma para ser entendida desde las lógicas empresariales de rentabilidad y eficiencia y los sistemas tecnológicos ofertados por el extensionista son entendidos como herramientas que dan garantías de éxito, aunque no las únicas a implementar. Y por último está el caficultor "transicional", aquel que se encuentra generando nuevas dinámicas a partir de la aplicación de sistemas tecnocientíficos y tradicionales, a la vez, que maneja estratégicamente su relación con la institucionalidad para hacerse beneficiario de

\footnotetext{
${ }^{34}$ Usamos las comillas, no para descalificar este tipo de conocimiento, sino para hacer evidente que es una categoría que proponen los caficultores en contraste con
}

programas de intervención sin cambiar del todo sus prácticas tradicionales, realizando, de este modo, reconfiguraciones a las prácticas agrícolas, de acuerdo con los conocimientos que mejor se ajusten a las circunstancias del momento. No obstante, estas formas de asumir las intervenciones tecnocientíficas se traslapan o conectan parcialmente (cf. Mol, 2007; Sting, 2015) y varían a lo largo de la historia de vida del productor de café. Con esta generalista clasificación se espera hacer evidente que el café, la finca y especialmente el caficultor no es un sujeto pasivo y susceptible de ser disciplinado dócilmente para articularlo a los flujos de capital transnacional; todo lo contrario, es un sujeto que contiene inconmensurables experiencias de la historia económica, política y ecológica del territorio colombiano cuyo valor no puede ser entendido solo en términos de rentabilidad y eficiencia.

\section{Conclusión}

Esta aproximación a entender el entramado de relaciones culturales, sociales, agrícolas y tecnocientíficas que reconfiguran la producción de café en la SNSM, nos invita a evadir la forma en que se ha entendido la transferencia y la apropiación social de la CyT, como un proceso lineal de transmisión y adopción de conocimientos y prácticas tecnocientíficos enfocados a públicos considerados no expertos, a través de diferentes estrategias para que, no solo incorporen tecnologías y conocimientos en sus vidas cotidianas, sino que lo hagan de la manera como los planificadores lo esperan. Esta forma lineal de entender la ASCyT tiene implícitas las ideas que: a) existe una relación directa entre el desarrollo tecnocientífico y el bienestar social; b) que los conocimientos de los "no expertos" no pueden contribuir satisfactoriamente a dicho bienestar social; y c) que estos sujetos son susceptibles de ser

los conocimientos que les llegan a través de los procesos de transferencia de tecnologías. 
disciplinados. Teniendo en cuenta lo anterior, se plantea que los procesos de transferencia y apropiación se pueden entender, no como "productos finales" que se adoptarán por los públicos no expertos, sino como elementos de diálogo para la negociación de la realidad en contextos social y políticamente heterogéneos; así mismo la ASCyT no sería el fin último del desarrollo científico sino una estrategia para evaluar con los diferentes actores las implicaciones de asumir tecnologías y conocimientos tecnocientíficos.

\section{Agradecimientos}

Agradecemos a la Federación Nacional de Cafeteros de Colombia y al Comité Departamental de Magdalena, concretamente al Dr. Edgar Ramírez y la ingeniería Isabel Ruiz, así como a cada uno de los extensionistas y funcionarios, ya que gracias a su apoyo fue posible el desarrollo de esta investigación. De igual forma agradecemos a las comunidades de Palmor y Río Piedras, así como a cada uno de los caficultores, sus esposas y familiares, quienes nos abrieron las puertas de sus casas y sus fincas para dialogar y vivir las experiencias en torno al café. Agradecemos a Ariel Amado, Laura Alfonso, Maquerlis Mendoza, Helena Avendaño y Carlos Parra (estudiantes de Antropología de la Universidad del Magdalena) por su apoyo en trabajo de campo. Agradecimientos especiales a los evaluadores anónimos por sus pertinentes observaciones que enriquecieron significativamente el artículo. Finalmente agradecer a Colciencias, la Gobernación del Magdalena y la Universidad del Magdalena por el apoyo brindado a través de la financiación de la Pasantía Jóvenes Investigadores 2015 de Mirleydis de la Hoz.

\section{Referencias}

Aceves. J. (1998). La historia oral y de vida: del recurso técnico a la experiencia de investigación. En J. Galindo (Coord.), Técnicas de investigación en sociedad, cultura y comunicación, (pp. 207-276). México: Pearson y Addison Wesley Longman.

Alvarado-Alvarado, G.; Moreno-González, E.; Montoya-Restrepo, E. y Alarcón-Suárez, R. (2009). Calidad física y en taza de los componentes de la variedad castillo ${ }^{\circledR}$ y sus derivadas regionales. Cenicafé, 60(3): 210-228.

Arcila, P., Farfán, V. Moreno B., Salazar, G e Hincapié. L.G. (2007). Sistemas de producción de café en Colombia. Bogotá: FNC-Cenicafé.

Avellaneda, M. y Pérez-Bustos, T. (2010). Tensiones y convergencias en torno a una apuesta de pluralidad de la apropiación social de la ciencia y la tecnología en Colombia. En Deslocalización de la apropiación social de la ciencia y la tecnología en Colombia. Aporte desde prácticas diversas. Bogotá: Colciencias, Maloka.

Barad, K. (1999). Agential Realism: feminist interventions in under- standing scienti $\mathrm{c}$ practices. En M. Biagioli (Ed.), The Science Studies Reader, (pp. 1-11). New York: Routledge.

Blaser, M. (2013). Un relato de la Globalización dese el Chaco. Popayán: Editorial Unicauca.

Blaser, M. (2009). La ontología política de un programa de caza sustentable. WAN $e$ journal, (4): 81-107.

Bortz, G. (2017). Biotecnología, (des)nutrición y desarrollo local: aprendizajes, producción de conocimientos y políticas públicas en la trayectoria del "yogurito Escolar” (Tucumán, Argentina). En J. Gibert, A. Gómez y R. Cancino, Ciencia, tecnología y sociedad en América Latina. La mirada de las nuevas generaciones. (pp. 33-62). Chile: Ril Editores.

CAIC. (2012). El Café, Capital Social Estratégico: Informe Final. Bogotá: Comisión de Ajuste de la Institucionalidad Cafetera.

Callon, M. (1999). Some elements of a sociology of translation: domestication of the 
Scallops and the Fishermen of St. Brieuc Bay (1986, abridged 1998). En M. Biagioli (Eds.), The Science Studies reader, (pp.6783). New York y Londres: Routledge.

Callon, M y Law, J. (1997). After the individual in society: Lessons on collectivity from Science, Technology and society. The Cadanian Journal of sociology, 22 (2):165-182.

Castells, M. (2002). La galaxia internet. Revista Bibliográfica y ciencias sociales, VII (374).

Cenicafé. (2012). Variedad Castillo: preguntas frecuentes. Boletín técnico 426. Manizales -Caldas: Cenicafé.

COLCIENCIAS. 2010a. Estrategia nacional de apropiación social de la ciencia, la tecnología e la innovación. Bogotá: Departamento administrativo de ciencia, tecnología e innovación COLCIENCIAS.

COLCIENCIAS. 2010b. Deslocalizando la apropiación social de la ciencia y la tecnología en Colombia: aportes desde prácticas diversas. Bogotá: Departamento Administrativo de ciencia, tecnología e innovación COLCIENCIAS.

Daza-Caicedo, S. et al. (2017). Hacia la medición del impacto de las prácticas de apropiación social de la ciencia y la tecnología: propuesta de una batería de indicadores. H st ia $C n, \quad d$ Mangu $h$ s $24(1): 145-164$.

De Certeau, M. (2000). La invención de lo cotidiano. Las artes de hacer I. México: Universidad Iberoamericana-Instituto Tecnológico y de Estudios Superiores de Occidente.

Domínguez, E.; Echeverry, J. y Castaño, M. (2013). Apropiación social del conocimiento: El papel de la comunicación. Colombia: Universidad de Antioquía.

Escobar, A. (2018). Otro posible es posible: caminando hacia las transiciones desde Abya Yala/afro/latino-América. Bogotá: Ediciones desde abajo.
Escobar. A. (2007). La invención del tercer mundo. Construcción y deconstrucción del desarrollo. Caracas: Fundación editorial el Perro y la rana.

Escobar, A. (1999a). ¿Viviendo en "Ciberia"? En El final del salvaje: Naturaleza, Cultura y Política en la antropología contemporánea, (pp. 319-326). Bogotá: Cerec- ICAH.

Escobar, A. (1999b). El Final el Salvaje: antropología y nuevas tecnologías. En El final del salvaje: Naturaleza, Cultura y Política en la antropología contemporánea, (pp. 327-352). Bogotá: Cerec- ICAH.

FNC (2018). Informe del Gerente. 86 Congreso Nacional de Cafeteros. Gerencia General. Bogotá: FNC.

FNC (2016a). Informe general del 83 Congreso Nacional de Cafeteros. Gerencia General FNC.

FNC (2016b). Plan Operativo Desarrollar Extensión Rural. Versión 3. Código: FEEXD-0014 (Documentación Interna).

FNC (2015). Métodos de Extensión Rural. Versión 5. Código: FE-EXD-0005 (Documentación Interna).

FNC. (2014). Informe de Comités Departamentales. Por la caficultura que queremos LXXX Congreso Nacional de Cafeteros. Bogotá: FNC.

FNC. (2013a). Informes de Comités Departamentales: Por una Caficultura Competitiva. LXXIX Congreso Nacional de cafeteros 2013. Bogotá: FNC.

FNC. (2012). Comportamiento de la industria cafetera colombiana 2012. FNC.

FNC. (2011). Informes de Comités Departamentales: Caficultura Climáticamente Inteligente LXXVI. Bogotá: FNC.

FNC. (2009). Comité departamental de cafeteros del Magdalena. Informes al Congreso cafetero de los Comités departamentales. (pp. 84-91). Bogotá: FNC. 
FNC (2008). Informes al congreso cafetero de los comités departamentales 2008. Bogota: FNC.

FNC. (1958). Manual de cafetero colombiano. Bogotá: Editorial Argra.

FNC-Cenicafé (2013a). Manual del Cafetero Colombiano: Investigación y tecnología para la sostenibilidad de la caficultura, Tomo 1. FNC-Cenicafé.

FNC-Cenicafé. (2013b). Manual del Cafetero Colombiano: Investigación y tecnología para la sostenibilidad de la caficultura, Tomo 2. FNC-Cenicafé.

FNC-Cenicafé. (2013c). Manual del Cafetero Colombiano: Investigación y tecnología para la sostenibilidad de la caficultura, Tomo 3. FNC-Cenicafé.

Friede, J. (1963). Colonos alemanes en la Sierra Nevada de Santa Marta. Informe de la Comisión. Revista Colombiana de Antropología, 12:(402-411).

Gaitán, A.; Villegas, C.; Rivillas, C.; Hincapié, E. y Arcila, J. (2011). Almácigos de café: calidad fitosanitaria, manejo y siembra en el campo. Avances técnicos Cenicafé 404. FNC-Cenicafé. http//www.cenicafé.org/es/documents/AV T404.pdf.

Galindo, J (1998). Etnografía. El oficio de la mirada y el sentido. En J. Galindo (Coord.), Técnicas de investigación en sociedad, cultura y comunicación, (pp. 347-384). México: Pearson y Addison Wesley Longman.

Gamboa, P.Y.; Mosquera, S.A. y Paz, I.E. (2013). Caracterización de taza de café especial en el municipio de Chachagüí, departamento de Nariño, Colombia. Biotecnología en el Sector Agropecuario y Agroindustrial, 11 (2): 85-92.

García, E., Gonzáles, J.C.; López, J.A.; Luján. J.L.; Martín, M.; Osorio, C. y Valdés, C. (2001). Ciencia, Tecnología y Sociedad: una aproximación conceptual. Organización de Estados Iberoamericanos para la Educación, la Ciencia y la Cultura (OEI). Madrid: OEI.
Gathani, S., Gomez, M., Sabates, R. y Stoelinga, D. (2015). The Effect of monitoring: how data collection type and frequency boosts participation and the adoption of best practices in a coffee agronomy training program in Rwanda. Evaluation Review, 39(6) 555-586.

Gil, LF.; Cárdenas, J. y Gómez, R. (2000). La enfermedad de las cerezas del Café-CBDcausadas por el hongo Colletotrichum Kahawae. Boletín de Sanidad Vegetal 27. Bogotá: FNC, Cenicafé, Ica.

Gómez, I.; Rodríguez, L.; Alarcón, L. (2015). Método Etnográfico y Trabajo Social: algunos aportes para las áreas de investigación e intervención social. Fermentum, Revista Venezolana de Sociología y Antropología, 15(44): 353366.

Guber, R. (2005). El Salvaje metropolitano. Reconstrucción del conocimiento social en el trabajo de campo. Buenos Aires: Paidos.

Haraway. D. (2004).

Testigo_modesto@segundo_milenio.Hom



Feminismo y tecnociencia. Barcelona: Editorial UOC.

Haraway. D. (1999). "Las promesas de los monstruos: una política regeneradora para otros inapropiados/bles" en Política y Sociedad, 30: 121-163.

Haraway. D. (1991). Ciencia, Cibords y mujeres. Madrid: Ediciones Cátedra

Hermelin, D. (2011). Un contexto para la comunicación pública de la ciencia y la tecnología en Colombia: de las herencias eurocéntricas a los modelos para la acción. Revista Co-herencia, 8(14):231-260.

Hine, Christine. 2004. Etnografía virtual. Barcelona: Editorial UOC. 210p.

Latour, B. (2007). Nunca fuimos modernos. Ensayo de antropología simétrica. Argentina: Siglo Veintiuno editores.

Latour, B. (2005). Reensamblar lo social. Una introducción a la teoría Actor- Red. Buenos Aires: Manantial. 
Latour, B. (2004). Politiques de la nature. Comment faire entrer les sciences en démocratie. Paris: La Découverte/Poche.

Latour, B. y Woolgar, S. (1995). La vida en el laboratorio: la construcción de los hechos científicos: Alianza Universidad S. A. Madrid

Law. J y Mol. A. (2008). El actor actuado. la oveja de Cumbria en 2001. Política y sociedad 45(3):75-92.

Lazzarato, M. (2006). Por una política menor. Acontecimiento y política en las sociedades de control. Madrid: Traficantes de sueños.

Lozano-Borda, M.; Pérez-Bustos, T.; y RoattaAcevedo, C. (2012). Deconstruyendo el modelo deficitario de la apropiación social de la ciencia y la tecnología en Colombia: el caso de la cartilla "Las Maticas de mi Huerta". Educar em Revista, (44): 93-109.

Marcus, G. (2001). Etnografía en/del sistema mundo. El surgimiento de la etnografía multilocal. Alteridades, 11 (22): 111-127.

Martínez-Dueñas, W. (2016). Flujos y redes multinaturales: Un recorrido por mundos no [solo] modernos en Puracé, Colombia. Popayán: Editorial Unicauca.

Martínez-Dueñas, W (2012). Quand le H20 et esprit de l'eau se recontrent: coexistence de plusierus mondes à Puracé, Colombie. Recherches amérindiennes au Québec, 42(2-3): 39-47.

Martínez-Dueñas W. A. \& Perafán, A. (2017). Pensando la conservación desde el multinaturalismo en una localidad indígena de los andes colombianos. Universitas Humanística, (84):77-107.

Martínez-Dueñas. W.A \& Perafán, A. (2018). Postsostenibilidad. Notas antropológicas para imaginar otros futuros posibles. Santa Marta: Editorial Unimagdalena.

Mol. A. (2007). The Body multiple: ontology inmedical practice. Durham y Londres: Duke University Press.

Monsalve, D. (1927). Colombia Cafetera. Información general de la República y estadística de la industria del café. Primera Edición. Barcelona.

Moreno, G. y Alvarado, G. (2000). La variedad Colombia: veinte años de adopción y comportamiento frente a nuevas razas de la roya del cafeto. Cenicafé_ChinchinaCaldas. Colombia.

Moreno-Seceña, J., Nava-Tablada, M. y Hernández-Sánchez, M. (2015). Actitud de cafeticultores sobre el manejo y conservación de suelos del sitio Ramsar, Cascadas de Texolo. Agricultura, sociedad y desarrollo. 12(4): 553-566.

Muñoz, L. (2012). Editorial: Fortalecimiento institucional: eje de la sostenibilidad para el sector cafetero colombiano. No 28. (pp. 5-13). FNC.

Perafán-Ledezma, A.L. (2013). Quinuas, redes y nuevas significaciones en contextos del "desarrollo": el caso de El Rosal, Cauca (Tesis de doctorado). Universidad del Cauca, Popayán, Colombia.

Perafán, A. L. y Martínez-Dueñas, W. A. (2016). Biopoder, desarrollo y alimentación en El Rosal, Cauca (Colombia). Revista Colombiana de Sociología, 39(2), 183201.

Perafán-Ledezma, A. L. Y Martínez-Dueñas, W. A. (2019). Descubriendo mundos: una introducción a la investigación antropológica. Santa Marta (Colombia): Editorial Universidad del Magdalena.

Pérez-Bustos, T. (2014). Feminización y pedagogías feministas. Muesos interactivos, ferias de ciencia y comunidades de software libre en el sur global. Bogotá: Editorial Universidad Javeriana.

Pérez-Bustos, T. (2010). Construyendo espacios de exclusividad: una aproximación etnográfica al papel y la experiencia de mujeres indias y colombianas en las comunidades locales de Software Libre. Universitas Humanística, 69, 115-137.

Posada Carbó, E. (1993). Más allá de los andes: las ramificaciones de la cultura cafetera en 
el Caribe Colombiano (1850-1950). Caravelle, (61): 155-164.

Pinch, T. Bijker, W. (2013). La construcción social de los hechos y de artefactos: o acerca de cómo la sociología de la ciencia y la sociología de la tecnología pueden beneficiarse mutuamente. En $\mathrm{H}$. Thomas y A. Buch (Coord.), Actos, actores y artefactos. Sociología de la tecnología. (pp.19-62). Argentina: Universidad Nacional de Quilmes

Rabinow, P. (1996). Artificialidad e ilustración: de la sociobiología a la biosocialidad. En J. Crary y S. Kwinter (eds.), Incorporaciones (pp. 201-222). Madrid: Ediciones Cátedra.

Restrepo, O. (2013). Proyecto ensamblado en Colombia. Bogotá: Universidad Nacional de Colombia.

Roatta, C. (2013). Un giro del servicio al cuidado en las prácticas para la apropiación social de la ciencia y la tecnología (ASCYT): retos metodológicos. Universitas Humanística, (76): 421-445.

Rose, N. (2007). Políticas de la vida. Biomedicina, poder y subjetividad en el siglo XXI. Argentina: Unipe: Editorial Universitaria/pensamiento contemporáneo.

Russi, B. (1998). Grupos de discusión. De la investigación social a la investigación reflexiva. En J. Galindo (Coord.), Técnicas de investigación en sociedad, cultura y comunicación, (pp. 75-116). México: Pearson y Addison Wesley Longman.

Sánchez-Clavijo L. M., Botero-Echeverri J. E., Vélez J. G. (2007). Estructura, diversidad y potencial para conservación de los sombríos en cafetales de tres localidades de Colombia. Cenicafé 58(4): 304-323.

Servicio Geológico Colombiano y Cenicafé. (2018). De la geología al café. Bogotá: Servicio Geológico Nacional y Cenicafé.

Sting, A. (2015). The mushroom at the end of the world. On the possibility of life in capitalins Ruins. Princeton y Oxford: Princeton University Press.
Tocancipá-Falla, J., Perafán, A. y MartínezDueñas W. A. (2016). Campesinos y Antropología en Colombia: algunos alcances y perspectivas actuales. En: J. Tocancipá-Falla (Ed.), Antropologías en Colombia: Tendencias y debates, (pp. 587607). Popayán: Editorial Universidad del Cauca.

Vargas, J.; Palacios, M.I.; Ocampo, J.G y Aguiar, J. (2017). La agricultura protegida, una tecnología en acción: sus trayectorias, genealogías y redes sociotécnicas. En J. Gibert, A. Gómez y R. Cancino (Eds), Ciencia, tecnología y sociedad en América Latina. La mirada de las nuevas generaciones. (pp. 89-117). Chile: Ril Editores.

Viloria, J. (2005). Sierra Nevada de Santa Marta: economía de sus recursos naturales. Documentos de trabajo sobre economía regional. Núm. 61. Cartagena: Banco de la República.

Viloria, J. (1998) El café en la Sierra Nevada de Santa Marta: Aspectos Históricos. Historia Caribe, Vol. II, Núm. 3, 1998.

Viloria, J. (1997). Café caribe: La economía cafetera en la Sierra Nevada de Santa Marta. Documentos de trabajo sobre economía regional. Núm. 1. Cartagena: Banco de la República.

Villarraga, A (2014). Dirección de acuerdos de la verdad. Región Caribe, Antioquia y Choco. Nuevos escenarios de conflicto armado $y$ violencia. Panorama posacuerdos con AUC. Bogotá: Centro Nacional de Memoria Histórica.

Vink, D. (2007). Ciencia y sociedad. Sociología del trabajo científico. España: Gedisa Editorial

Winner, 1. (1995). Constructivismo social: abriendo la caja negra y encontrándola vacía. En J. M. Iranzo; J.R. Blanco T. Gonzáles, C. Torres y A. Cotillo, Sociología de la ciencia y la tecnología, (pp.305-318). Madrid: SCIC.

Winner, L. (1985). "Do artifacts have politics"? En MacKensi et al. (eds.), The social 
shaping of technology. Philadelphia: Open University Press.

SICA. (2017). Zona cafetera departamento del Magdalena. Federación Nacional de Cafeteros. Sistema de información Cafetera - Sica.

Tudela, J. (2015). Caracterización socioeconómica y ambiental de la producción de café orgánico en Perú. Rev.
Investig. Altoandin, 17(1):23-32. DOI: http://dx.doi.org/10.18271/ria.2015.73

Zapata, M. y Marín, B. (2015). Ruralidad y dispositivos móviles: apropiación social y uso de la tableta de información cafetera TIC. Estudio de caso Federación Nacional de Cafeteros para Antioquia. Revista Lasallista de investigación, 12 (2):19-27. 